\title{
Asset pricing implications of a New Keynesian model
}

\author{
Bianca De Paoli, Alasdair Scott and Olaf Weeken* \\ First draft: 21 May 2006 \\ This draft: 14 August 2006 \\ PRELIMINARY AND INCOMPLETE
}

\begin{abstract}
To match the stylised facts of goods and labour markets, the canonical New Keynesian model augments the optimising neoclassical growth model with nominal and real rigidities. We ask what the implications of this type of model are for asset prices. Using a second-order numerical solution to the model, we examine bond and equity returns, the equity risk premium, and the behaviour of the real and nominal term structure. We catalogue the factors that are most important for determining the size of risk premia and the slope and level of the yield curve. In a world of technology shocks only, increasing the degree of real rigidities raises risk premia and increasing nominal rigidities reduces risk premia. In a world of monetary policy shocks only, both real and nominal rigidities raise risk premia. The results indicate that the implications of the New Keynesian model for average asset returns depend critically on the characterisation of shocks hitting the model economy.
\end{abstract}

Keywords: asset prices, New Keynesian, rigidities

JEL classification: E43, E44, E52, G12

*Monetary Analysis, Bank of England, Threadneedle St., London EC2 R 8AH, United Kingdom. The authors thank the participants at the conference on Computing in Economics and Finance, Cyprus, June 2006, for helpful comments. The views expressed in this paper are those of the authors and do not necessarily reflect views held by the Bank of England. 


\section{Introduction}

This paper examines the asset pricing implications of a New Keynesian model. Our aim is to link asset returns and risk premia to macroeconomic fundamentals of shocks and the intrinsic dynamics of the model. To this end, we take a macroeconomic model and solve for the unconditional expectations of the risk-free real interest rate, the return on equity, the equity risk premium, and real and nominal term structures. We attempt to explain the marginal effects of key New Keynesian features, by varying the weight on consumption and labour habits and the strength of capital and price adjustment costs. We also explore how the results depend on the relative importance of monetary and productivity shocks. As in previous studies, when there are only productivity shocks, increasing the degree of real rigidities raises risk premia. We find, however, that, when there are only technology shocks, increasing the degree of nominal rigidities reduces risk premia. In a world of monetary policy shocks only, both real and nominal rigidities raise risk premia. The results indicate that the implications of the New Keynesian model for average asset returns depend critically on the characterisation of shocks hitting the economy.

Our motivation for this exercise is that considerable effort has been made to matching New Keynesian models to goods and labour market data, but less attention has been paid to matching asset market facts. Typically, these models depict optimising households and firms operating in monopolistically competitive goods and labour markets. Real and nominal rigidities have been found to be important to match the observed persistence in the data. Devices such as habits and adjustment costs have been found useful to 'tune' the impulse responses to match those found in statistical models such as VARs. ${ }^{1}$ But it would be hard to have faith in a model that led to totally counterfactual asset pricing implications, and, since New Keynesian models have increasingly been advocated as a platform for policy advice, it seems important to at least understand their implications for asset prices.

The model embeds a consumption-based capital asset pricing model, such that asset prices depend on marginal (consumption) utility and payoffs. Hence, there is little in this paper that is new, over and above the classic contributions in the finance literature that receive excellent treatments in summaries by Campbell (1999) and others. But in our set-up, payoffs are generated by the interactions of agents in goods and labour markets, instead of being imposed exogenously through endowment processes. In this respect, we draw on two strands of literature. The first has explored the implications of production economies with capital for asset prices. Examples include den Haan (1995), Lettau (2003), Jermann (1998), Boldrin, Christiano and Fisher (2001), and Uhlig (2004). The last three of these papers point to the importance of real frictions for asset prices. A second strand has focused more on the implications of nominal shocks for the term structure, with an emphasis on the role of inflation risk premia. Examples include Sangiorgi and Santoro (2005)

\footnotetext{
${ }^{1}$ See, for example, Christiano, Eichenbaum and Evans (2005).
} 
and Hördahl et al (2005). They find, encouragingly, that the same sorts of nominal rigidities embodied in New Keynesian models also help to account for the nominal yield curve and inflation risk premia. However, for simplicity, these models have abstracted from capital by assuming that production is simply linear in labour. Our contribution is to draw these contributions together.

We stress that this essay is not an attempt to solve asset pricing puzzles. Indeed, one could ask why bother to look at asset prices in general equilibrium, when even partial equilibrium models struggle to fit asset pricing facts. Instead, it is a much more modest attempt to try to gain some understanding of the asset price behaviour in an increasingly-dominant macroeconomic paradigm, so we take the model as given. At the same time, there is no single New Keynesian model, and we cannot begin to cover all variations that are currently used. We hope, however, to use a model that is representative and therefore that the results are useful for those who use similar models, especially in policy environments.

In the following Section, we present a brief summary of some benchmark stylised facts. Section 3 explains how the experiments will proceed, including a discussion of the solution method, the model, its parameterisation, and the equilibrium conditions for asset prices that we use. The properties of asset returns are discussed in detail in Section 4, and concluding comments are contained in Section 5. Appendices list the model, parameter values, and more details of the experiments of Section 4 .

\section{Stylised facts of asset returns}

The literature identifies a large number of stylised facts across assets and across countries. These include the level and volatility of stock returns, short term and long term interest rates, their excess returns and their comovement with real activity data such as consumption. We include these below for illustration, although no attempt is made in what follows to derive a model that best matches these facts.

1. Ex-post real stock returns are high and volatile: the average real stock return has been 7.6 per cent with a standard deviation of 15.5 per cent. $\dagger$

2. Ex-post real returns on risk-free assets are much lower and less volatile: the average real return on 3 -months rates has been 0.8 per cent with a standard deviation of 1.8 per cent. $\dagger$

3. Quarterly consumption growth is very smooth and not well forecasted by its own history: the standard deviation of the growth rate of real consumption of non-durables and services is 1.1 per cent, with a first order autocorrelation of the growth rate at 0.2 per cent. $\dagger$

4. The correlation of real consumption growth and real stock returns is low, at 0.2 per cent. $\dagger \ddagger$ 
5. Returns on equities are more volatile than returns on bonds: the excess return of equities over the risk-free rate is 15.2 per cent, compared to 8.9 per cent for the excess return of bonds over the risk-free rate. $\dagger$

6. Nominal yields are higher than real yields $\ddagger$ and the nominal $† \S$ and real $\ddagger$ yield curves are on average upward sloping: the difference between the yield on longterm bonds and 3-month rates - the term premium - is about 120 basis points. $\dagger \S$

7. The volatilities of nominal $£$ and ex ante realf yields are nearly invariant to maturity: the standard deviation of nominal 3-month rates is 2.7 per cent compared to 2.4 per cent for ten-year yields. $\S$

(Sources: $\dagger$ Campbell (1999), Tables 2, 3,4 and 7. Campbell reports data across a number of countries. The stylised facts and data quoted here refer to quarterly US data from 1947 to 1996. $\ddagger$ Den Haan (1995), Figures 1 and 2. The stylised facts and data reported refer to quarterly US data from 1960 to 1988. § Hördahl et. al. (2005), Table 1a. The stylised facts and date reported refer to quarterly US data from 1960 to 1997.)

\section{The model and method}

To generate and understand the asset pricing implications of our New Keynesian model, we: (i) specify the model; (ii) choose parameter values; (iii) solve the model numerically to a second-order approximation; (iv) look at the stochastic averages of key endogenous variables, such as asset returns; and (v) test the sensitivity of these moments to variations in key parameters that control the dynamic behaviour of the model, referring to asset pricing expressions, impulse responses, and the model's reduced form where appropriate.

\subsection{General equilibrium asset pricing solutions for a New Keynesian model}

Theory tells us that differences in asset prices are driven by uncertainty about future payoffs. But it is common to linearise macroeconomic models to first-order, which imposes certainty equivalence and therefore identical expected returns for all assets. Ideally, we would like to solve for the functions that are the solutions to stochastic nonlinear expectational difference equations, but this is hampered by the curse of dimensionality. "Global" solution methods (such as projection methods) are therefore intractable for macro models that have many state variables, which is the case with a typical New Keynesian model.

An alternative approach, which we could term the "linear/lognormal" approach, exploits the recursive nature of asset pricing equations by first linearising the equi- 
librium conditions of the macro model as usual, and then assuming that the arguments in the relevant asset pricing equations are distributed jointly lognormally and evaluating them separately. Examples include Jermann (1998), Lettau (2003), and $\mathrm{Wu}$ (2005). An advantage of this approach is that linearised conditions can often yield great insight. However, analytical solutions are not easy and transparent for a New Keynesian model with rigidities and capital. Moreover, the linear/loglinear approach implies an inconsistent treatment of the model's economics: for example, the precautionary savings motive that affects yields at different maturities is ignored when approximating consumption behaviour.

In what follows, we solve the model numerically using second order perturbation methods. $^{2}$ The solution is similar to results one would get under the lognormality assumption, as first and second moments are the sole determinants of the equilibrium conditions. ${ }^{3} \quad$ This approach is quick and tractable, and solves the whole model simultaneously. ${ }^{4}$ A potential disadvantage is that, by using a "black box" solution method, we lose insight into the fundamental economics behind the results. To mitigate this problem, we will refer to analytical second order expressions where helpful.

\subsection{The model}

A full derivation of the model is presented in Appendix A. We model households, firms and a government in a closed economy. Households and firms optimise while the government behaves according to simple rules. Goods [and labour] markets are noncompetitive; monopolistic competition leads to mark-ups over marginal costs. Monopoly power implies that goods [and labour] providers can fix prices, which facilitates the addition of nominal price [and wage] stickiness. In turn, changes in nominal monetary instruments (in this model, the short nominal interest rate) can have real effects. ${ }^{5}$ Asset markets are competitive, efficient and frictionless.

Households participate in goods, labour and asset markets. They are assumed to be infinitely lived and to make rational decisions based on all current information. Each household, indexed by $a$, maximises utility defined over the consumption of a

\footnotetext{
${ }^{2}$ See Judd (1998) and Schmidt-Grohe and Uribe (2004). We use the algorithms implemented in the Dynare freeware for Matlab available at http://www.cepremap.cnrs.fr/dynare/. Code is available from the authors on request.

${ }^{3}$ However, they are not identical, because the second-order approach leads to time-invariant risk premia, even in the presence of devices such as consumption habits. Since we are only looking at implications for stochastic averages in this paper, this property does not affect the analysis.

${ }^{4}$ In separate testing, we have confirmed that the perturbation method accurately reproduces the results from projection methods described in Jermann (1998). See also Collard and Juillard (2001) for an application of perturbation methods to asset pricing problems. Of course, the approach assumes that the model is sufficiently "smooth" that a second order approximation will be sufficiently accurate to describe the first and second moments of the model.

${ }^{5}$ Hence, the model embodies the so-called "monetary mark-up" framework; see Rotemberg and Woodford (1999).
} 
composite nondurable good, $C$, and real money balances, $M / P{ }^{6}{ }^{6}$ while minimising disutility of labour effort, $N$ :

$$
E_{t} \sum_{i=0}^{\infty} \beta^{i} U\left(\begin{array}{c}
\frac{\left(C_{t+i}(a)-H_{t+i}^{C}(a)\right)^{1-\gamma^{C}}-1}{1-\gamma^{C}} \\
-\frac{\left(N_{t+i}(a)-H_{t+i}^{N}(a)\right)^{1+\gamma^{N}}-1}{1+\gamma^{N}} \\
+\frac{\left(\frac{M_{t+i}(a)}{P_{t+i}}\right)^{1-\gamma^{M}}-1}{1-\gamma^{M}}
\end{array}\right),
$$

where $\beta \in(0,1)$ is the subjective discount factor measuring households' impatience, $\gamma^{C}$ is the coefficient of risk aversion for households and the inverse of the intertemporal elasticity of consumption, ${ }^{7} \gamma^{N}$ is the inverse of the intertemporal elasticity of labour, and $\gamma^{M}$ is the inverse of the intertemporal elasticity of real money balances. $H_{t+i}^{C}$ and $H_{t+i}^{N}$ denotes external consumption and labour habit levels, respectively. ${ }^{8} \mathrm{~A}$ household's period-by-period budget constraint is given by

$$
\begin{aligned}
& C_{t}(a)+\frac{T_{t}(a)}{P_{t}}+\frac{M_{t}(a)}{P_{t}}+\frac{V_{t}^{e q}}{P_{t}} S_{t}(a) \\
& +\sum_{j=1}^{J} \frac{V_{j, t}^{b n}}{P_{t}} B_{j, t}^{n}(a)+\sum_{j=1}^{J} V_{j, t}^{b r} B_{j, t}^{r}(a) \\
= & \frac{W_{t}}{P_{t}} N_{t}(a)+\frac{M_{t-1}(a)}{P_{t}}+\frac{V_{t}^{e q}+D_{t}}{P_{t}} S_{t-1}(a) \\
& +\sum_{j=1}^{J} \frac{V_{j-1, t}^{b n}}{P_{t}} B_{j, t-1}^{n}(a)+\sum_{j=1}^{J} V_{j-1, t}^{b r} B_{j, t-1}^{r}(a) .
\end{aligned}
$$

Household revenue includes labour income and the current values of financial assets held over from the previous period. During the discrete period, households supply $N$ units of labour, for which they each receive the market nominal wage, $W$. Financial assets include money, $M$; a share in an equity index, $S$, which is a claim on a portion of all firms' profits; and nominal and real zero-coupon bonds of maturities ranging from $j=1$ to $J$, denoted by $B_{j}^{n}$ for a $j$-period nominal bond and $B_{j}^{r}$ for a $j$-period real

\footnotetext{
${ }^{6}$ We could, however, have a "money-less" nominal model, with no change to the results that follow - see Woodford (2003).

${ }^{7}$ But see Campbell and Cochrane (1999).

${ }^{8}$ For the sake of working with a "reasonable" coefficient of relative risk aversion, we do not restrict ourselves to log utility. Utility is additive, which is more common in the New Keynesian literature than multiplicative specifications. Together, however, these assumptions would imply that the model did not have a balanced growth equilibrium - see King et al. (1988). We therefore abstract from growth, which raises an inconsistency vis à vis the level of interest rates. Using a form of multiplicative utility would allow us to assume non-zero growth, but we prefer to use a utility specification that is more common in the New Keynesian literature (see, for example, Smets and Wouters 2003).
} 
bond. Nominal bonds pay out one unit of money at the end of their maturity, and real bonds pay one unit of consumption. The values of the equity share index, nominal bonds and real bonds are denoted by $V^{e q}, V_{j}^{b n}$ and $V_{j}^{b r}$, respectively. ${ }^{9}$ Households also receive dividends from firms, $D$ (which are paid in money). Stocks and bonds from the previous period are revalued at the start of the new discrete period; we can think of them being sold off at the beginning of the new period. Households expenditures include consumption, $C$, lump-sum taxes, $T$, and a new portfolio of financial assets in each period: money, stocks and bonds.

[Nominal wage stickiness and labour market clearing condition to be added.]

Monopolistically-competitive intermediate-goods firms maximise profits. Following Rotemberg (1982), we assume that firms want to avoid changing their price $P(z)$ at a rate different than the steady-state gross inflation rate, $\bar{\Pi}$. Doing so incurs an intangible cost that does not affect cashflow (hence, profits) but enters the maximisation problem as a form of "disutility":

$$
\max E_{t} \sum_{i=0}^{\infty} \beta^{i} \frac{\Psi_{t+i}(z)}{\Psi_{t}(z)}\left\{D_{t+i}(z)-\frac{\chi^{P}}{2}\left(\frac{P_{t+i}(z)}{\bar{\Pi} P_{t+i-1}(z)}-1\right)^{2} P_{t+i} Y_{t+i}\right\},
$$

where $\beta^{i} \frac{\Psi_{t+i}(z)}{\Psi_{t}(z)}$ is the $z$ th firm's stochastic discount factor, $P$ is the general price level, $\bar{\pi}$ is the steady-state inflation rate, $Y$ is output, and $\chi^{P}$ measures the cost of adjusting prices. ${ }^{10}$ Profits are the difference between revenue and expenses of paying for workers and investment and are immediately paid out as dividends, $D(z)$, to shareholders:

$$
D_{t+i}(z)=P_{t+i}(z) Y_{t+i}(z)-W_{t+i} N_{t+i}(z)-P_{t+i} I_{t+i}(z)
$$

As usual in a typical New Keynesian model, firms do not therefore retain earnings, nor do firms accumulate inventories, both of which could potentially affect dividend flows and the value of the firm.

Each firm produces output $Y(z)$ by combining predetermined capital stock and currently rented labour in a Cobb-Douglas technology. ${ }^{11}$ They face downward-sloping

\footnotetext{
${ }^{9}$ Note that $V^{e q}$ and $V^{b n}$ are denominated in nominal goods (units of money), whereas $V^{b r}$ is denominated in real goods (units of consumption).

${ }^{10}$ We use the price adjustment costs, rather than the more common Calvo (1983) specification for price rigidities. Examples of Rotemberg costs include Ireland (2001), Edge et al. (2003) and Harrison et al. (2005). In the latter, the adjustment costs are intangible; see Pesenti (2003) for an example of where they are tangible. The difference is important, exactly because of the effects on cashflows and dividends. We choose to make the effects intangible to focus on other effects from price rigidities.

${ }^{11}$ In this model, capital is firm specific (Altig et al. (2003) and Sveen et al. (2003)) and has to be installed in previous period for current production. Equivalently, we could specify a version in which capital is owned by households and rented to firms. The firm-specific characterisation does allow for a slightly more transparent depiction of dividends and equity prices.
} 
demand curves

$$
Y_{t+i}(z)=\left(\frac{P_{t+i}(z)}{P_{t+i}}\right)^{-\eta_{t}} Y_{t+i}
$$

and incur costs $\omega\left(I_{t+i}(z), K_{t+i-1}(z)\right)$ when changing the capital stock, with the capital accumulation identity given by

$$
K_{t+i}(z)=(1-\delta) K_{t+i-1}(z)+\omega\left(I_{t+i}(z), K_{t+i-1}(z)\right) K_{t+i-1}(z) .
$$

As is standard in the literature, we assume that $\omega(\cdot)$ is concave, with the functional form following Jermann (1998) and Uhlig (2004). ${ }^{12}$

Competitive final goods firms ("retailers") combine differentiated outputs into a composite good for use as consumption or investment. ${ }^{13}$

In this model, government is minimal. The nominal government budget constraint is given by

$$
T_{t}=M_{t}-M_{t-1} .
$$

The government thus makes net transfer payments to the public that are financed by printing money. A central bank follows a simple instrument rule:

$$
R_{1, t}^{c b}=\left(R_{1, t-1}^{c b}\right)^{\theta^{R}}\left(\frac{\bar{\Pi}}{\beta}\right)^{1-\theta^{R}}\left(\frac{\Pi_{t}}{\bar{\Pi}}\right)^{\theta^{\Pi}\left(1-\theta^{R}\right)} e^{\varepsilon_{t}^{R}},
$$

where $\theta^{R} \in[0,1)$ governs the degree of interest rate smoothing, $\theta^{\Pi}>1$ governs the degree to which the central bank reacts to deviations of inflation from steady state. Alternatively, we can write the above expression as follows:

$$
r_{1, t}^{c b}=\theta^{R} r_{1, t-1}^{c b}+\left(1-\theta^{R}\right) \theta^{\pi} \pi_{t}+\varepsilon_{t}^{R},
$$

where lower case letters denote log deviations from steady-state.

There is a large number of potential variations to this structure: rental vs firmspecific capital; cash-in-advance vs money-in-utility vs moneyless specifications; internal vs external habits; capital adjustment costs vs time-to-build or plan; Calvo vs Rotemberg vs Taylor contracts; and many others. We cannot cover all possible variations, and aim here for specification that is broadly representative.

Similarly, it is common now to include a large number of shocks when fitting these models to the data. We focus on two shocks that have received the most attention: technology and monetary policy. The level of productivity is assumed to follow a stable $\operatorname{AR}(1)$ process with shock term $\varepsilon^{Z}$; monetary policy shocks, $\varepsilon^{R}$, are introduced into the rule (8).

\footnotetext{
${ }^{12}$ See Beaubrun and Tripier (2005) for an alternative formulation.

${ }^{13}$ We do not need to assume the existence of final goods firms. We could equivalently assume that households consume a basket of goods that has the same properties. In that case, we would need a similar assumption for aggregate investment by firms.
} 


\subsection{Parameterisation}

There is also large range of variation for parameter values. We do not attempt to find a parameterisation that best matches stylised business cycle and asset pricing facts. Instead, we use standard values in the literature. Much of the baseline calibration of the real side of the model follows Jermann (1998), who in turn bases his calibration on some of the classic articles in the real business cycle literature. The calibration of the monetary side of the model borrows from a number of authors (e.g. Ireland (2001)). Since this literature has focused primarily on data for the United States, the calibration below should also be consistent with the stylised asset pricing facts for the United States reported in Section 2. A summary of the baseline calibration is provided in Appendix B.

\subsubsection{Parameters affecting the deterministic steady state}

The subjective discount factor $\beta$ is calibrated at 0.99 , implying an annualised deterministic steady state interest rate of about 4 per cent. The constant capital share in the production function $\alpha$ is set to 0.36 and the depreciation rate $\delta$ is set at 0.025 , implying an annualised depreciation rate of about 10 per cent. The curvature parameter on consumption $\gamma^{C}$ which measures relative risk aversion is set to 5 . And the parameter governing the external consumption habit $\chi^{C}$ is set at 0.82 .

Jermann (1998) does not include labour-leisure choice and for symmetry, we set the curvature parameter on labour $\gamma^{N}$ to the same level as the curvature parameter on consumption (a parameter value of 2.5 in our disutility over labour specification equates to a parameter of 5 in a utility of leisure specification). Similar to the consumption habit, the parameter governing the labour habit $\chi^{N}$ is set to 0.82 . In addition, as is standard in the literature, the labour parameter $\theta^{N}$ is calibrated such that the in the steady state one third of the labour endowment is spend on productive activity.

Preferences over real money balances are also merely set for symmetry, with the parameter governing the curvature of the utility function with respect to real money balances $\gamma^{M}$ set at 5. The price elasticity of demand $\eta$ is set at 6 as in Ireland (2001), implying steady state markup of $\iota=\frac{\eta}{\eta-1}=1.20$ or 20 per cent This is within the range of assumptions in the literature that range from around 10 per cent to 40 per cent (see Keen and Wang (1995)).

\subsubsection{Parameters that only affect the dynamic adjustment}

The parameters for the non-monetary sector again follow Jermann (1998), with the technology shock highly persistent $\left(\rho^{A}=0.95\right)$ and the standard deviation of the shock innovation $\sigma_{\varepsilon^{A}}$ implying volatility of output growth of about 1 per cent.

The capital adjustment costs parameter $\chi^{K}$ measures the elasticity of the investment capital ratio with respect to Tobin's q (see Lettau (2003)). We set $\chi^{K}=0.30$, 
with $\chi^{K} \rightarrow \infty$ implying zero adjustment costs and $\chi^{K} \rightarrow 0$ implying infinite adjustment costs. ${ }^{14}$

There is little empirical evidence that directly points to the calibration for the price adjustment cost parameter $\chi^{P}$. We follow Ireland (2001) and chose $\chi^{P}=77$. Keen and Wang (1995) show how the Rotemberg (1982) price adjustment cost parameter can be linked to the Calvo (1983) parameter, with our baseline calibration implying that about 0.2 per cent of firms can reoptimising each period, which in turn translates into an average frequency of price reoptimisation of between 13 and 15 months. ${ }^{15}$

\subsection{Uncertainty and risk sharing in the New Keynesian model}

In this model, intermediate firms set prices and employ factors identically in a symmetric equilibrium (see Walsh, 2003). Dividends and wages are therefore identical across firms. Hence, consumers do not face any idiosyncratic risks. ${ }^{16}$ This allows us to talk about a representative consumer. On the further assumption that the law of one price holds in asset markets, this implies a unique stochastic discount factor. Households own all firms via shareholdings and the economy is closed; the stochastic discount factor of firms is therefore the stochastic discount factor of households. ${ }^{17}$

However, the economy is stochastic, facing shocks to economy-wide productivity and monetary policy. On the real side, households will engage in precautionary savings, such that the level of consumption is lower the higher is uncertainty about future marginal utility of wealth. On the nominal side, price-setting firms charge a mark-up over expected real marginal costs. When we take into account the effects of uncertainty, the concavity of the cost function implies that monopolistically-competitive firms will also take into account the uncertainty of expected costs and demand. ${ }^{18}$

Our analysis in what follows therefore focuses on how asset returns reflect this aggregate uncertainty.

\footnotetext{
${ }^{14}$ This implies somewhat less price stickiness as in Jermann (1998), who sets $\chi^{K}=0.23$.

${ }^{15}$ Keen and Wang (1995) show that the log-linear pricing equations have the same form under both Calvo (1983) and Rotemberg (1982) pricing. In particular, using the notation employed here, the Rotemberg (1982) price adjustmennt cost parameter $\chi^{P}$ is given by $\chi^{P}=\frac{(\eta-1) \kappa}{(1-\kappa)(1-\beta \kappa)}$, where $\eta$ is the price elasticity of demand, $\beta$ is the subjective discount factor and $(1-\kappa)$ is fraction of firms reoptimising in Calvo (1983), implying an average frequency of price reoptimisation of $\frac{1}{(1-\kappa)}$.

${ }^{16}$ If we assumed that prices [and wages] were reset following the Calvo (1983) scheme, then households would face idiosyncratic risks to wages and dividends, depending on which firm they happened to work for and which shares they happened to own. In these models, it is conventional to assume each household is assumed to hold state-contingent securities that yield net payments $O$ in consumption goods each period and fully insure the household against idiosyncratic consumption risk (see Erceg, Henderson and Levin 2003). We also abstract from investment risk by assuming that the share, $S$, in the household budget constraint (2) is of an equity index.

${ }^{17}$ See Danthine and Donaldson (2004) for an example in which this does not have to hold.

${ }^{18}$ This effect has only been noted in New Keynesian models, to our knowledge, in some of the New Open Economy Macro literature: see, for example, Devereux and Engle (2000, p17).
} 


\subsection{Asset prices and returns}

Before looking at the numerical results, in this section we aim to review some general principles on asset pricing and establish what to look for in the properties of the macro model.

We know that the utility-maximising behaviour of households embeds a consumptionCAPM framework in the model. That is, all assets will be valued recursively, according to the equilibrium pricing equation $P^{i}=E\left[S D F \cdot X^{i}\right]$, where $X^{i}$ represents the payoff from asset $i, P^{i}$ is its price, and $S D F$ is the stochastic discount factor or pricing kernel. In our model, there are three versions of this basic asset pricing equation: first, the value of an indexed bond of maturity $j$,

$$
V_{j, t}^{b r}=E_{t}\left[S D F_{t+1} V_{j-1, t+1}^{b r}\right], \quad j=1, . ., J
$$

second, the real value of a nominal bond of maturity $j$,

$$
\frac{V_{j, t}^{b n}}{P_{t}}=E_{t}\left[S D F_{t+1} \frac{V_{j-1, t+1}^{b n}}{P_{t+1}}\right], \quad j=1, . ., J ;
$$

and finally the real value of equity shares,

$$
\frac{V_{t}^{e q}}{P_{t}}=E_{t}\left[S D F_{t+1} \frac{V_{t+1}^{e q}+D_{t+1}}{P_{t+1}}\right],
$$

where the stochastic discount factor is $S D F_{t+1}=\beta \frac{\Lambda_{t+1}}{\Lambda_{t}}$ and marginal utility is $\Lambda_{t}=$ $\left(C_{t}-\chi^{C} C_{t-1}\right)^{-\gamma^{C}}$ (see Appendix A for derivations). ${ }^{19}$ Because a real zero-coupon bond returns one unit of consumption at maturity, for $j=1$ (10) becomes

$$
1=E_{t}\left[S D F_{t+1} \frac{1}{V_{1, t}^{b r}}\right]=E_{t}\left[S D F_{t+1}\right] R_{1, t+1}^{b r},
$$

where $R_{1, t+1}^{b r}=\frac{1}{V_{1, t}^{b r}}$ is the risk-free real interest rate. ${ }^{20}$ For $j=2$, equation (10) becomes

$$
1=E_{t}\left[\beta \frac{\Lambda_{t+1}}{\Lambda_{t}} \frac{V_{1, t+1}^{b r}}{V_{2, t}^{b r}}\right] .
$$

The term $V_{1, t+1}^{b r}$ on the right-hand-side of the above equation is the price of a real bond of original maturity $j=2$ with one period left to maturity. Assuming no arbitrage, this price will equal the price of a bond of maturity $j=1$ issued next period. Bond

\footnotetext{
${ }^{19}$ The existence of a representative agent and the assumption of efficient asset markets confirms the conditions for the existence of a unique SDF; see Cochrane (2001, chapter 4).

${ }^{20}$ Note that this is the return from period $t$ to $t+1$, and it is known at $t$ (see Appendix A). We will therefore refer to this as the risk-free rate of return.
} 
prices (and from them yields) can thus be defined recursively, with the real price and real yield for any real bond of maturity $j$ given by

$$
1=E_{t}\left[\beta \frac{\Lambda_{t+1}}{\Lambda_{t}} \frac{V_{j-1, t+1}^{b r}}{V_{j, t}^{b r}}\right],
$$

and

$$
R_{j, t+1}^{b r}=\left(V_{j, t}^{b r}\right)^{-\frac{1}{j}}
$$

Nominal bond prices and nominal yields can be calculated in the same fashion from equation (11), with the nominal prices and nominal yields for a one-period and for a $j$-period bond given by

$$
V_{1, t}^{b n}=E_{t}\left[\beta \frac{\Lambda_{t+1}}{\Lambda_{t}} \frac{1}{\Pi_{t+1}}\right]
$$

and

$$
R_{1, t+1}^{b n} \equiv \frac{1}{V_{1, t}^{b n}}
$$

Correspondingly,

$$
V_{j, t}^{b n}=E_{t}\left[\beta \frac{\Lambda_{t+1}}{\Lambda_{t}} \frac{1}{\Pi_{t+1}} V_{j-1, t+1}^{b n}\right]
$$

and

$$
R_{j, t+1}^{b n}=\left(V_{j, t}^{b n}\right)^{-\frac{1}{j}}
$$

We also define the one-period real holding period return on equity, $R^{e q}, \operatorname{as}^{21}$

$$
R_{t+1}^{e q}=\frac{V_{t+1}^{e q}+D_{t+1}}{V_{t}^{e q}} \frac{1}{\Pi_{t+1}} .
$$

To explore the factors driving asset returns in this model, we derive a second order approximation to the above equations. We express variables in log deviations from steady-state, and denote them in lower case (more specifically, $x=\ln (X / \bar{X})$ ). Using (12) and (15), we obtain the following expression for the unconditional mean ${ }^{22}$ of equity returns:

$$
E\left[r_{t+1}^{e q}\right] \simeq-E\left[s d f_{t+1}\right]-\frac{1}{2} \operatorname{var}\left(s d f_{t+1}\right)-\operatorname{cov}\left(s d f_{t+1}, r_{t+1}^{e q}\right)-\frac{1}{2} \operatorname{var}\left(r_{t+1}^{e q}\right),
$$

where $s d f_{t, t+j} \equiv \ln \left(\frac{\Lambda_{t+j}}{\Lambda_{t}}\right)$. In the case of a one-period real bond, which pays out the consumption bundle in the next period, we have

$$
r_{1, t+1}^{b r} \simeq-E\left[s d f_{t+1}\right]-\frac{1}{2} \operatorname{var}\left(s d f_{t+1}\right)
$$

\footnotetext{
${ }^{21}$ Note that this is a return from period $t$ to $t+1$, which in this case - unlike the one-period real bond return - is unknown at time $t$.

${ }^{22}$ The expressions are written in terms of unconditional moments in order to be consistent with the illustrations shown in the next Section.
} 
The variance term on the right hand side represents the precautionary savings motive. An increase in consumption volatility that increases precautionary savings will therefore reduce the mean of the real interest rate ${ }^{23}$. Subtracting (17) from (16) defines the excess return of equities over risk-free bonds - the equity risk premium, or $E R P-$ as

$$
E\left[r_{t+1}^{e q}-r_{1, t+1}^{b r}\right] \simeq-\operatorname{cov}\left(s d f_{t+1}, r_{t+1}^{e q}\right)-\frac{1}{2} \operatorname{var}\left(r_{t+1}^{e q}\right)
$$

Note that the variance term in the right hand side of the above equation arises from the Jensen's inequality from taking logs of returns. The equity risk premium is the negative of the covariance of the stochastic discount factor with the return on equities. Hence, the equity risk premium will be positive if equity returns are expected to be low when the stochastic discount factor is high, and vice versa. That is, if returns are low, when they are most wanted (i.e. when marginal utility is increasing), investors will require a premium to hold equities. Moreover, a more volatile stochastic discount factor and/or a more volatile equity return will increase the magnitude of the equity risk premium.

Returning to bonds, equation (13) implies that

$$
R_{j, t+1}^{b r}=\left(E_{t}\left[\beta \frac{\Lambda_{t+j}}{\Lambda_{t}}\right]\right)^{-\frac{1}{j}}
$$

Approximating the above equation to second-order and expressing the variables in log deviations from steady-state, we have:

$$
r_{j, t+1}^{b r} \simeq-\frac{1}{j}\left(E\left[s d f_{t, t+j}\right]+\frac{1}{2} \operatorname{var}\left(s d f_{t, t+j}\right)\right) .
$$

This expression implies that the yield on any bond will always be below the deterministic steady state level. Note that in our case, where we have abstracted from growth, $E\left[s d f_{t, t+j}\right]=0$.

We can use (19) to examine the real term premium, the difference between the return on a longer-term real bond and the one-period real bond. The average yield spread between real bond of maturity $j$ and one-period real bond is, therefore,

$$
E\left[r_{j, t+1}^{b r}-r_{1, t+1}^{b r}\right] \simeq \frac{1}{2}\left(\operatorname{var}\left(s d f_{t+1}\right)-\frac{\operatorname{var}\left(s d f_{t, t+j}\right)}{j}\right)
$$

Whether the real yield curve is upward or downward sloping will depend on whether the term on the right hand side of (20) is positive or negative. If the growth rate of marginal utility is positively autocorrelated, such that the numerator $\operatorname{var}\left(s d f_{t, t+j}\right)$ rises faster than $j$, then the yield curve is downward sloping. That is, if a "bad" shock is expected to be followed by other bad events, risk averse investors appreciate

\footnotetext{
${ }^{23}$ Note that these expressions, derived from second-order approximations, are similar to the ones presented in den Haan (1995), under the assumption of joint log-normality of the relevant variables.
} 
locking-in today a given return in the future, and therefore longer-term bonds serve as a form of insurance. This points us to examine the autocorrelation of impulse responses of the stochastic discount factor.

The same logic can be applied to the nominal term structure. The net yield for a nominal bond of maturity $j$ can be written as

$r_{j, t+1}^{b n} \simeq \frac{1}{j}\left[-E\left[s d f_{t, t+j}\right]+E\left[\pi_{t, t+j}\right]-\frac{1}{2} \operatorname{var}\left(\pi_{t, t+j}\right)-\frac{1}{2} \operatorname{var}\left(s d f_{t, t+j}\right)+\operatorname{cov}\left(s d f_{t, t+j}, \pi_{t, t+j}\right)\right]$

where $\pi_{t, t+j} \equiv \ln \left(P_{t+j} / P_{t}\right)$ is a gross compounded inflation rate over $j$ periods. Therefore, the difference between the one-period nominal rate and the real risk-free rate is

$$
E\left[r_{1, t+1}^{b n}-r_{1, t+1}^{b r}\right] \simeq E\left[\pi_{t, t+1}\right]-\frac{1}{2} \operatorname{var}\left(\pi_{t+1}\right)+\operatorname{cov}\left(s d f_{t+1}, \pi_{t+1}\right),
$$

where $E\left[\pi_{t, t+1}\right]$ is the stochastic average inflation rate. Both the expected real and nominal interest rates embed a precautionary savings motive. An increase in consumption volatility that increases precautionary savings will therefore reduce both the mean of the real and nominal interest rates by the same amount. But the nominal interest rate is also affected by three other factors. The first of these is the steady-state inflation rate. This is zero in our benchmark calibration in the deterministic steady state, but can differ from zero in the stochastic steady state. The second term on the right hand side is a Jensen's inequality term that will increase as the variability of inflation increases, thus lowering the mean nominal yield. The covariance term measures the inflation risk premium: if inflation is high when the value of extra consumption is high (i.e. the covariance term is positive), the risk premium is positive. The reason is that high inflation reduces the real return of the nominal bond at a time when a high real return would be valued highly by the consumer. This implies that we should examine the impulse responses of marginal utility and inflation to see the effects of inflation risk premia across maturities. More generally, the relative position of the nominal and real yield curves will depend on the following factors: the magnitude of the Jensen's inequality term (determined by the size of inflation variability); the steady-state level of inflation; and the sign and size of the inflation risk premium.

The average yield spread between a $j$-period and a one-period nominal bond can be written as

$$
\begin{aligned}
E\left[r_{j, t+1}^{b n}-r_{1, t+1}^{b n}\right]= & E\left[r_{j, t+1}^{b r}-r_{1, t+1}^{b r}\right]+\frac{1}{2}\left(\operatorname{var}\left(\pi_{t+1}\right)-\frac{1}{j} \operatorname{var}\left(\pi_{t, t+j}\right)\right) \\
& -\left(\operatorname{cov}\left(s d f_{t+1}, \pi_{t+1}\right)-\frac{1}{j} \operatorname{cov}\left(s d f_{t, t+j}, \pi_{t, t+j}\right)\right)
\end{aligned}
$$

The slope of the nominal structure will depend on the slope of the real term structure, the relative size of the Jensen's inequality effect at different maturities and the relative 
size of inflation risk premia at different maturities. The variance term in equation (23) will be negative if $\operatorname{var}\left(\pi_{t, t+j}\right)$ increases faster than $j$, the maturity of the bond. This will be the case if inflation is positively correlated. Equation (23) shows that the nominal term structure can be downward sloping, even with an upward-sloping real structure.

This analysis emphasises that, to understand the implications for asset returns and risk premia, we need to understand the variances and covariances of the stochastic discount factor and asset returns. In the finance literature, these are usually taken as given, but evaluating these moments is more difficult when these are outcomes of a macroeconomic system. Nonetheless, these moments can be thought of as product of (a) size of the shocks, and (b) transmission of the shocks. ${ }^{24}$ This suggests that much insight can be gained by looking at impulse responses. These will show the importance of rigidities on real consumption and real returns. Previous studies using simpler models (e.g., Jermann (1998) and Boldrin, Christiano and Fisher (2001)) have noted that real rigidities that make it more difficult for agents to smooth consumption in the face of shocks will show up in a higher equity risk premium. This suggests that more real rigidity will translate into higher equity and term premia. We examine the implications of real and nominal rigidities for asset prices in the next Section.

\section{Asset prices and rigidities in the New Keynesian model}

In this section, we aim to explain the implications of real and nominal rigidities in the New Keynesian model for asset returns. We use the model described in Section 3.2, along with the asset pricing equations discussed in Section 3.5. We show how the average risk-free real interest rate, the return on equity, the equity premium, the term spread and real and nominal yield curves change with variations in parameters that affect the dynamic properties of the model. We also show how impulse responses of relevant variables are affected.

We start by analysing the case in which prices are perfectly flexible; since monetary policy has no real effects, we focus on productivity shocks and study the asset pricing implications of changes on the degree of real rigidities. When nominal rigidities are introduced, we analyse the role of nominal and real rigidities, investigating the role of productivity and monetary policy shocks.

\footnotetext{
${ }^{24}$ For an analytical demonstration in the case of the RBC model, see Lettau (2003).
} 


\subsection{Flexible price model}

\subsubsection{Productivity shocks}

In this section, we study the behaviour of asset prices in a world of productivity shocks, under the assumption that prices are perfectly flexible (that is, we impose the restriction that $\left.\chi^{P}=0\right)$. Table 1 presents stochastic averages of output, capital stock, investment, consumption, the real wage and employment, and thus provide a snapshot of the implications of uncertainty for the goods and labour markets.

Precautionary savings imply that the capital stock and investment flows are higher in the stochastic than in the deterministic steady state. Consumption is smaller both in absolute terms and as a proportion of output. Real wages are higher as higher capital levels raise the marginal product of labour, and this induces agents to work more hours.

Stochastic averages for equity returns and the yields on one-year and ten-year real and nominal bonds are shown in Table 2. We also report the average equity risk premium, term spread and inflation risk premium.

The differences between the deterministic and stochastic state-state values of the short interest rates are explained by precautionary savings. As expected, precaution implies that, in the stochastic steady state, capital accumulation is higher and the risk-less real interest rate is lower than if there were no uncertainty.

The real return on equity is higher than both the deterministic real return and the stochastic average riskless real interest rate, implying a positive equity risk premium. ${ }^{25}$ This result can be understood from the impulse responses to the productivity shock. ${ }^{26}$ Figure 1 shows the impulse response of output, capital, investment, consumption, employment and real wages following a productivity shock, while Figure 2 illustrates how marginal utility, the stochastic discount factor, equity returns, the risk-free rate, the value of equity shares and dividends respond to this disturbance.

The shock is persistent, and so causes persistent increases in consumption, investment, real wages and the value of the firm. The positive productivity shock reduces dividends on impact. ${ }^{27}$ The momentary fall in dividends is not enough to offset the (forward-looking) valuation of the firm, however. Therefore, the return on holding equities increases when the shock hits. By construction from the specification of preferences, the rise in consumption causes an immediate fall in the stochastic discount factor. Hence the stochastic discount factor and the return on equity are negatively correlated, which is a prerequisite for a positive equity risk premium.

The effects on real interest rates are different from what we might expect from

\footnotetext{
${ }^{25}$ Note that the equity risk premium is defined as the difference between the real return on equity and the real risk-free rate. As a result it includes a Jensen's inequality effect.

${ }^{26}$ Note that the impulse responses for the model approximated to second order are the same as those of the model approximated to first order: second order terms are time invariant and therefore should not affect dynamic responses.

${ }^{27}$ Note that they fall because of a rise in wages, not because of rising investment.
} 
a model with no real rigidities. There we would expect interest rates to rise, to crowd out consumption and investment demand sufficiently to meet available supply. In contrast, in this model, the real interest rate falls on impact. The difference is explained by the degree of capital adjustment costs and consumption habits - the responses of consumption and investment on impact are so small, relative to the shock to productivity, that interest rates in this case have to fall to clear savings-investment.

Table 2 also shows that in the presence of uncertainty, the inflation risk premium is positive; a positive productivity shock causes a fall in inflation, with the inflation rate and the stochastic discount factor thus positively correlated. ${ }^{28}$ As discussed above (22), this implies a negative correlation between the stochastic discount factor and the real return on the nominal bond and thus a positive inflation risk premium.

In the absence of uncertainty, and given symmetric shocks, the average term structure would be flat. Figure 3 shows, however, that the stochastic average of the real term structure is upward sloping. As is clear from equation (20) in Section 3.5 , the profile of the term structure depends on whether uncertainty about future marginal utility (and hence the precautionary savings motive) is proportionally larger or smaller as maturity increases.

To explore this further, consider first what would happen in the case where there are no consumption habits, so that marginal utility is a function of the level of consumption. If consumption growth is positively correlated, shocks in the growth rate are persistent. Uncertainty about levels of consumption grows rapidly, more rapidly than the denominator in (20), the maturity of the bond. This implies a downward-sloping real term structure - real long bonds are regarded as insurance, and carry a negative term premium. This feature of the standard neoclassical growth model has been noted by den Haan (1995) and Lettau (2003), and this implication of positively-correlated consumption growth (as reported in Section 2) is incompatible with upward-sloping real and nominal term structures.

In our model, with a high degree of consumption habits, marginal utility is defined over near-changes in consumption. We can see from the impulse responses that, while through most of the period the level of consumption is positively correlated, the stochastic discount factor is negatively correlated. Agents who believe this model will see that it implies mean reversion in marginal utility. Hence, as shown in Figure 3 , the real term structure is upward sloping - i.e., there is less of a precautionary motive to invest in longer maturity bonds, which means a smaller subtractive term from the deterministic rate, which implies a positive real term premium. ${ }^{29}$ An investor given the choice of investing in real long bonds or rolling over real short bonds views committing to real long bonds as relatively risky, and so real long bonds carry a positive term premium.

Understanding what determines the level and shape of the nominal term structure

\footnotetext{
${ }^{28}$ Note that, when prices are flexible, the evolution of inflation is soly driven by the policy rule, which responds to movements in real variables.

${ }^{29}$ This point has been made by Wachter (2006).
} 
is more complex. As seen in Figure 3, the nominal yield curve is always below the deterministic interest rate, as the average inflation rate is close to the inflation target of zero inflation, and the Jensen's inequality term pushes down on the nominal term structure. The slope of the nominal term structure is determined by the slope of the real yield curve, the autocorrelation of inflation and the evolution of the covariance between inflation and the stochastic discount factor trough time (equivalently, the slope of the curve depends on the autocorrelation of the nominal stochastic discount factor). Under our benchmark calibration, the nominal term structure is initially upward sloping and then downward sloping.

\subsubsection{Sensitivity analysis: the role of real rigidities in a world of produc- tivity shocks}

In the previous section we have seen that the negative correlation between the return on equity and the stochastic discount factor imply a positive equity risk premium; the negative autocorrelation in the stochastic discount factor implies an upward sloping real yield curve and a positive term premium; and the precautionary saving motive reduces the risk-free rate. But what determines the size of precautionary savings and the magnitude of the term and equity premia is the degree of macroeconomic uncertainty. In this section we assess the contribution of real side rigidities to volatility in the relevant variables. We compare the results from our standard calibration to cases when consumption habits, labour habits and/or capital adjustment costs are switched off. These are presented in Table 3.

First, in the case when there are no frictions, the model exhibits the classic equity and term premia puzzles of Mehra and Prescott (1985) and Backus et al (1989), respectively. To address this problem, experience with matching the consumption CAPM framework to the data has emphasised the need for some sort of state contingency in utility to induce sufficient volatility to the stochastic discount factor. As has been demonstrated by Campbell and Cochrane (1999) in the context of endowment economies, consumption habits can be used for this. However, column three shows that by switching capital adjustment costs off ${ }^{30}$, we confirm previous results by Jermann (1998) and Boldrin, Christiano and Fisher (2001) that, in a production economy, consumption habits by themselves are not sufficient: consumer-investors who inhabit our model can "self-insure" by owning capital; if the real economy is frictionless, they can direct production to achieve a sufficiently smooth consumption stream. In other words, we need to ensure that households not merely dislike consumption volatility, they have to be prevented from doing something about it; rigidities in the form of capital adjustment costs are one modeling device to achieve this.

In our model, we extend the analysis by the aforementioned authors by including

\footnotetext{
${ }^{30}$ Note that our specification of capital adjustment costs means that they cannot be completely switched off. In this exercise we use $\chi^{K}=30,000$.
} 
labour rigidities in the form of labour habits. With no labour habits (column four), risk premia are low. But a comparison of the third and fourth columns in Table 3 indicates that capital adjustment costs contribute more to risk premia. (This suggests that capital per se plays an important role, even though its role for explaining business cycle fluctuations has previously been downplayed. ${ }^{31}$ )

Figure 4 shows how the volatility of the stochastic discount factor, inflation and returns varies with changes in the degree of consumption habit persistence over a range from no habits $\left(\chi^{C}=0\right)$ to a high degree of persistence $\left(\chi^{C}=0.80\right)$. As expected, for given level of the labour habit and capital rigidities, a higher degree of consumption habit persistence (the darker lines) implies more volatility in the stochastic discount factor and returns. Figure 5 shows the implications of this variation of the consumption habit for the equity risk premium, the risk-free rate, the real term premium, the inflation risk premium and the real and nominal term structure. It shows that the higher volatility of the stochastic discount factor and returns is reflected in a higher real term premium, inflation risk premium and equity risk premium. In contrast, the risk-free rate is lower, reflecting higher precautionary savings. Increasing the size of the labour habits parameter and the level of capital adjustment costs has similar implications.

Note that these conclusions, especially as regards the slope of the yield curve, do depend on the assumption of trend stationarity (see Labadie (1994)). It is standard in macro models to impose trend stationarity, but other detrending assumptions are possible; see Hansen (1997) for discussion.

\subsubsection{Monetary policy shocks}

We should note that when prices are perfectly flexible, the dynamics of the real economy is only affected by real shocks and monetary policy is irrelevant. Monetary policy shocks have a one-off effect in the inflation rate, and are completely irrelevant for the rest of the economy. In this case, as shown in Figure 6, the real term structure is flat and nominal yield curve lies below the real yield curve. The difference between the two curves is driven by the inflation variability term in equation (22) (i.e. the Jensen's inequality term).

\subsection{Sticky price model}

We now move to the case in which prices are sticky and analyse the role of nominal rigidities for asset returns. We begin by examining the sticky-price version of the model with productivity shocks only, and then look at the same versions with monetary policy shocks only.

\footnotetext{
${ }^{31}$ See Campbell (1994, p481).
} 


\subsubsection{Productivity shocks}

Figures 7 and 8 show the impulse response functions of key economic variables and asset prices to a productivity shock in the sticky price model. Table 4 shows the unconditional moments of the real and nominal one-year and ten-year rates. It also presents the return on equity, the equity risk premium, the term spread and the inflation risk premium.

A comparison of table 4 with table 2 shows that sticky prices imply a smaller equity risk premium, a smaller inflation risk premium, a higher real risk-free rate, and smaller term premia (i.e. the real and nominal yield curve are flatter). These facts will be explored in the next section, which analyses the sensitivity of asset returns to changes in nominal rigidities. As in the flex-price model, the negative autocorrelation in the growth rate of marginal utility (equivalently, the stochastic discount factor) generates a real term structure that is on average upward sloping (see Figure 9). Similarly, the nominal term structure is initially upward sloping and then downward sloping.

\subsubsection{Sensitivity analysis: the role of nominal rigidities in a world of pro- ductivity shocks}

The previous analysis showed that real rigidities make it more difficult for an economy to deal with aggregate shocks; this is reflected by asset returns in higher risk premia. These findings raise the questions as to whether the same intuition holds for nominal rigidities.

In the case of a world driven solely by technology shocks, the answer is no: raising the degree of price stickiness reduces equity and term premia. This can be seen in Figures 10 and 11, where the darker responses indicate higher degrees of nominal rigidity. In the flex-price case $\left(\chi^{P}=0\right)$, with a vertical aggregate supply curve, a given supply shock leads to larger fluctuations in output than if the supply curve was flatter. This can be seen in the impulse responses for the stochastic discount factor and the return on equity, which have less amplitude as the degree of price stickiness rises.

Figure 11 shows that the size of the equity premium falls as price stickiness is increased from $\chi^{P}=0$ to $\chi^{P}=80$. Lower volatility of marginal utility also reduces precautionary savings, so that the average real risk-free rate rises with the degree of price rigidity. Because an increase in price rigidity also implies that the stochastic discount factor is less negatively autocorrelated, the slope of the yield curve flattens. Equivalently, since marginal utility growth is known to be mean reverting, so that yields of higher maturity asymptote to the deterministic real interest rate, the term spread must fall with the rise in the risk-free real rate.

In a world of productivity shocks, inflation and the stochastic discount factor are positively correlated, implying a positive inflation risk premium. However, by dampening both the variance of inflation and the stochastic discount factor (figure 
10), the inflation risk premium falls with higher price stickiness (figure 11).

\subsubsection{Monetary policy shocks}

When prices are sticky, the real economy will be affected by monetary policy shocks. This can be seen from the impulse responses in Figures 12 and 13, which illustrate reactions to a positive (i.e., contractionary) shock to the monetary policy rule (8). The shock reduces output, consumption and real wages and increases marginal utility. As illustrated in Table 5, when the economy is subject to monetary policy shocks only, the inflation risk premium is negative. This is because consumption and inflation are positively correlated in a world of demand shocks. ${ }^{32}$ When marginal utility is high, inflation is low, with the implication that the real return on the nominal asset is high when high real returns are highly valued. As a result, the nominal asset provides insurance and the inflation risk premium is negative.

\subsubsection{Sensitivity analysis: the role of nominal rigidities in a world of mon- etary policy shocks}

In the case of a world driven solely by monetary policy shocks, raising the degree of price stickiness increases equity and term premia. This can be seen in Figures 15 and 16. A monetary policy shock has no effect on output in the flex-price case, with its vertical aggregate supply curve, and therefore zero effect on consumption and asset returns. As the degree of price stickiness rises, the supply curve flattens and more of the demand shock is accommodated by fluctuations in real variables. This can be seen in the impulse responses for consumption, the stochastic discount factor and the return on equity, which have a greater amplitude as the degree of price stickiness rises. The equity risk premium is therefore higher. With this increase in volatility comes an increase in precautionary saving and a reduction in the real risk-free rate.

As price rigidities rise, the variance of inflation falls but the variance of the stochastic discount factor rises. The change in the inflation risk premium as the degree of price rigidity varies is therefore hard to predict. In this model, under our benchmark calibration, the reduction in the variance of inflation dominates the increase in the variance of the stochastic discount factor and the inflation risk premium falls (i.e. becomes less negative).

\subsection{The role of the monetary reaction function}

These results are conditional upon the assumptions we make about the structure of the economy, as understood by consumer-investors. It is worth emphasising that an integral part of that structure is the monetary reaction function. The clear implication is that changes in the systematic behaviour of the monetary authority will affect

\footnotetext{
${ }^{32}$ This is conditional on the reaction of the monetary authority, which in this model accomodates inflation a little.
} 
asset returns, in addition to the direct effects from monetary policy shocks. There are also important implications for the real and nominal term structures: Piazzesi and Scheider (2006) show that whether the nominal curve slopes up or down depends on whether inflation is perceived as bad for growth.

There is also a potential role for inflation target shocks: increased uncertainty about policy objectives would mean increased compensation to hold assets that pay nominal returns. We leave a thorough examination of the role of the monetary authority for a separate paper. ${ }^{33}$

\section{Conclusions}

This paper has confirmed a previous result, established in the context of real business cycle models, that capital adjustment costs are an important factor in achieving quantitatively significant equity and term premia. We have shown how risk premia in the New Keynesian model rise as consumption habits and capital adjustment costs rise. Our results with labour habits suggest that adding any friction in production that increases real volatility will increase risk premia.

The New Keynesian model adds two dimensions: nominal rigidities and nominal shocks. We have considered only one nominal rigidities and one extra shock, an idiosyncratic monetary policy shock. Even with this small marginal extension, an important result emerges: the relationship between risk premia and nominal rigidities depends on the source of the shock. Intuitively, in a world of monetary policy shocks only, stickier prices mean more of the shock has to be accommodated by adjustments in real consumption and returns, and therefore risk premia rise. However, in a world of productivity shocks only, stickier prices dampen some of the movement in output, so causing falls in risk premia. We plan to extend this analysis to investigate whether other shocks popular in the New Keynesian literature can be categorised as "supply" or "demand", depending on their effects on risk premia with variations in New Keynesian rigidities.

In an attempt at greatest possible clarity, we have posed stark alternatives in this paper and have avoided taking a view on the "right" mix and correlation of shocks hitting the economy. The analysis in this paper suggests that it might be possible to use unconditional moments of asset returns to help identify the mix.

There are also many areas where we could usefully extend the structure of the model economy. For example, we have only considered the case of power utility, which has some stark assumptions for asset returns. ${ }^{34}$ A logical alternative is a non-recursive form such as the Epstein-Zin (1989) specification used by Tallarini (2000) in an RBC model and by Piazzesi and Schneider (2006) for examining bond

\footnotetext{
${ }^{33}$ See Ravenna and Seppala (2005).

${ }^{34}$ For example, it implies that average stochastic yields are always below the deterministic level set by preferences and the trend growth rate.
} 
yields. Perhaps more important is the question of risk premia in New Keynesian open economy models. An established literature has worked with asset returns in real endowment models, following Lucas' (1982) islands. This would confront an empirical question of the degree and nature of international risk sharing. ${ }^{35}$

A further avenue to explore is to look at conditional moments, with a view to examining what the New Keynesian model says about time variation in risk premia in response to shocks. This would involve looking at third order effects.

${ }^{35}$ See, for example, Baxter and Jermann (1997) vs Brandt et al. (2005). 


\section{References}

[1] Altig, David, Christiano, Lawrence J., Eichenbaum, Martin and Lindé, Jesper (2005) "Firm-specific capital, nominal rigidities, and the business cycle", NBER Working Papers 11034.

[2] Backus, David K., Allan W. Gregory and Stanley E. Zin (1989), Journal of Monetary Economics, 24, pages 371-399.

[3] Baxter, Marianne and Urban Jermann (1997), "The international diversification puzzle is worse than you think." American Economic Review 87, 170-191.

[4] Bayoumi, Tamim, Douglas Laxton, Hamid Faruqee, Benjamin Hunt, Philippe Karam, Jaewoo Lee, Alessandro Rebucci, and Ivan Tchakarov (2004), "GEM: A new international macroeconomic model", International Monetary Fund Occassional Paper 239.

[5] Beaubrun-Diant, Kevin E. and Fabien Tripier (2005), "Asset returns and business cycles in models with investment adjustment costs." Economics Letters 86, 141-146.

[6] Boldrin, Michele, Lawrence J. Christiano and Jonas D.M. Fisher (2001), "Habit persistence, asset returns, and the business cycle." American Economic Review 91(1), 149-166.

[7] Brandt, Michael W, John H. Cochrane and Pedro Santa-Clara (2005), "International risk sharing is better than you think, or exchange rates are too smooth." manuscript.

[8] Calvo, Guillermo A. (1983), "Staggered prices in a utility-maximising framework" Journal of Monetary Economics 12(3), 383-398.

[9] Campbell, John Y. (1994), "Inspecting the mechanism: an analytical approach to the stochastic growth model", Journal of Monetary Economics 33, 463-506

[10] Campbell, John Y. (1999), "Asset Prices, Consumption, and the Business Cycle", Chapter 19 in John Taylor and Michael Woodford eds., Handbook of Macroeconomics, Amsterdam: North-Holland, 1999.

[11] Campbell, John Y. and John H. Cochrane (1999), "By force of habit: A consumption-based explanation of aggregate stock market behavior", Journal of Political Economy 107, 205-251.

[12] Christiano, Lawrence J., Martin Eichenbaum and Charles Evans (2005), "Nominal rigidities and the dynamic effects of a shock to monetary policy." forthcoming, Journal of Political Economy. 
[13] Cochrane, John H. (2001), Asset pricing, Princeton and Oxford: Princeton University Press

[14] Cochrane, John H. (2006), "Financial markets and the real economy", manuscript, available at http://gsbwww.uchicago.edu /fac/john.cochrane/research /Papers/cochrane_financial_and_real_update.pdf.

[15] Collard, Fabrice and Michel Juillard (2001), "Accuracy of stochastic perturbation methods: the case of asset pricing models", Journal of Economic Dynamics And Control 25(6/7), 979-999.

[16] Danthine, Jean-Pierre and John B. Donaldson (2004), "The macroeconomics of delegated management," manuscript, available at http://www.hec.unil.ch/jdanthine/working\%20papers/dmfinal.pdf

[17] den Haan, Wouter (1995), "The term structure of interest rates in real and monetary economies", Journal of Economic Dynamics and Control 19(5/6), 909940.

[18] Devereux, Michael B. and Engel, Charles (2000) "Monetary Policy in the Open Economy Revisited: Price Setting and Exchange Rate Flexibility" NBER Working Papers 7665.

[19] Edge, Rochelle, Thomas Laubach and John C. Williams (2003), "The responses of wages and prices to technology shocks" Federal Reserve Board of Governors Finance and Economics Discussion Series 2003-65.

[20] Erceg, Christopher J., Dale W. Henderson and Andrew T. Levin (2000), "Optimal monetary policy with staggered wage and price setting", Journal of Monetary Economics 46, 281-313.

[21] Epstein L G and Zin S E (1989), 'Substitution, risk aversion and the temporal behavior of consumption and asst returns: a theoretical framework', Econometrica, Vol. 57, No. 4, pages 937-969

[22] Hansen, Gary D. (1997), "Technical progress and aggregate fluctuations", Journal of Economic Dynamics and Control 21(6), 1005-1023.

[23] Harrison, Richard, Kalin Nikolov, Meghan Quinn, Gareth Ramsay, Alasdair Scott and Ryland Thomas (2005), The Bank of England Quarterly Model, London: Bank of England.

[24] Hördahl, Peter, Oreste Tristani and David Vestin (2005), "The yield curve and macroeconomic dynamics", manuscript, European Central Bank.

[25] Ireland, Peter N. (2001), "Sticky-price models of the business cycle: specification and stability", Journal of Monetary Economics 47, 3-18 
[26] Jermann, Urban J. (1998), "Asset pricing in production economies." Journal of Monetary Economics 41, 257-275.

[27] Jordá, Oscar and Kevin D. Salyer (2001), "The response of term rates to monetary policy uncertainty." manuscript, University of California, Davis.

[28] Judd, Kenneth L. (1998), Numerical Methods in Economics, Cambridge, MA: The MIT Press.

[29] Keen, Benjamin D. and Youngsheng Wang (2005), "What is a realistic value for price adjustment costs in New Keynesian Models?", manuscript

[30] King, Robert, Sergio Rebelo and Charles Plosser (1988), "Production, growth and business cycles I: The basic neoclassical model," Journal of Monetary Economics 21, 95-232.

[31] Labadie, Pamela (1994), "The term structure of interest rates over the business cycle." Journal of Economic Dynamics and Control 18, 671-697.

[32] Lettau, Martin (2003), "Inspecting the mechanism: closed-form solutions for asset prices in real business cycle models." Economic Journal 113, 550-575.

[33] Lioui, Abraham and Patrice Poncet (2004), "General equilibrium real and nominal interest rates." Journal of Banking and Finance 28, 1569-1595.

[34] Lucas Robert, E. Jr. (1982), "Interest rates and currency prices in a two country world", Journal of Monetary Economics 10, pages 335-60.

[35] Mehra R and Presscott E (1985), 'The equity premium puzzle', Journal of Monetary Economics 15, Pages 145-161.

[36] Pesenti, Paolo A., (2003) "The Global Economy Model(GEM): Theoretical Framework," forthcoming IMF Working Paper.

[37] Piazzesi, Monika and Martin Schneider (2006), "Equilibrium yield curves", forthcoming, NBER Macroeconomics Annual.

[38] Ravenna, Federico, and Juha Seppälä (2005), "Monetary policy and the term structure of interest rates." manuscript, University of California, Santa Cruz.

[39] Rotemberg, Julio J. (1982), "Monopolistic price adjustment and aggregate output," Review of Economic Studies 49, 517-531.

[40] Rotemberg, Julio J. and Michael Woodford (1999), "The cyclical behavior of prices and costs," Chapter in John Taylor and Michael Woodford eds., Handbook of Macroeconomics, Amsterdam: North-Holland, 1999. 
[41] Sangiorgi Francesco and Sergio Santoro (2005), "Nominal rigidities and asset pricing in New Keynesian monetary models", manuscript, available at http://www.collegiocarloalberto.it/english/Ricerca/sangiorgi/sangiorgi.pdf;

[42] Schmitt-Grohé, Stephanie and Martin Uribe (2004), "Solving dynamic general equilibrium models using a second-order approximation to the policy function," Journal of Economic Dynamics and Control 28, 755-775.

[43] Smets, Frank and Raf Wouters (2003), "An estimated dynamic stochastic general equilibrium model of the euro area", Journal of the European Economic Association 1(5), 1123-1175.

[44] Sveen, Tommy, and Lutz Weinke (2003), "Inflation and output dynamics with firm-owned capital", Universitat Pompeu Fabra Working Paper 702.

[45] Tallarini T D (2000), 'Risk-sensitive real business cycles', Journal of Monetary Economics, 45, pages 507-532

[46] Uhlig, Harald (2004), "Macroeconomics and asset markets: some mutual implications." manuscript, Humbolt University.

[47] Wachter, Jessica A. (2006), "A consumption-based model of the term structure", Journal of Financial Economics 79, 365-399.

[48] Walsh, Carl E. (2003), Monetary Theory and Policy, Cambridge, MA: The MIT Press.

[49] Woodford, Michael (2003), Interest and Prices: Foundations of a Theory of Monetary Policy, Princeton: Princeton University Press.

[50] Wu, Tao (2005), "Macro factors and the affine term structure of interest rates", forthcoming, Journal of Money, Credit and Banking. 


\section{A Model derivation}

A note on timing: in what follows, all stocks are recorded at the end of the discrete period. Hence, the money stock at the beginning of period $t$ is dated $M_{t-1}$, for example. All variables with lags are therefore predetermined.

\section{A.1 Households}

The economy is inhabited by a large number of households, indexed by $a$. They each have identical preferences defined over the consumption of a composite good, $C$; leisure, $L$; and real money balances, $M / P$ :

$$
E_{t} \sum_{i=0}^{\infty} \beta^{i} U\left(C_{t+i}(a), L_{t+i}(a), \frac{M_{t+i}(a)}{P_{t+i}}\right),
$$

where $\beta \in(0,1)$ is the subjective discount factor measuring households' impatience. Time available for work and leisure is normalised to one, so that

$$
L_{t+i}(a)=1-N_{t+i}(a) .
$$

The utility function is given by

$$
\begin{aligned}
& \frac{\left(C_{t+i}(a)-H_{t+i}^{C}(a)\right)^{1-\gamma^{C}}-1}{1-\gamma^{C}} \\
& -\frac{\left(N_{t+i}(a)-H_{t+i}^{N}(a)\right)^{1+\gamma^{N}}-1}{1+\gamma^{N}} \\
& +\frac{\left(\frac{M_{t+i}(a)}{P_{t+i}}\right)^{1-\gamma^{M}}-1}{1-\gamma^{M}}
\end{aligned}
$$

where $H^{C}$ represents an external consumption habit and $H^{N}$ is a corresponding habit in leisure. Households' period-by-period budget constraint is given by

$$
\begin{aligned}
& C_{t}(a)+\frac{T_{t}(a)}{P_{t}}+\frac{M_{t}(a)}{P_{t}}+\frac{V_{t}^{e q}}{P_{t}} S_{t}(a) \\
& +\sum_{j=1}^{J} \frac{V_{j, t}^{b n}}{P_{t}} B_{j, t}^{n}(a)+\sum_{j=1}^{J} V_{j, t}^{b r} B_{j, t}^{r}(a) \\
= & \frac{W_{t}}{P_{t}} N_{t}(a)+\frac{M_{t-1}(a)}{P_{t}}+\frac{V_{t}^{e q}+D_{t}}{P_{t}} S_{t-1}(a) \\
& +\sum_{j=1}^{J} \frac{V_{j-1, t}^{b n}}{P_{t}} B_{j, t-1}^{n}(a)+\sum_{j=1}^{J} V_{j-1, t}^{b r} B_{j, t-1}^{r}(a) .
\end{aligned}
$$


On the right hand side, we have labour income and the current values of financial assets held over from the previous period. During the discrete period, households supply $N$ units of labour, for which they each receive the market nominal wage, $W$. Financial assets include money, $M$; a share in an equity index, which is a claim on a portion of all firms' profits, $S$; and nominal and real zero-coupon bonds of maturities ranging from $j=1$ to $J$, denoted by $B_{j}^{n}$ for a $j$-period nominal bond and $B_{j}^{r}$ for a $j$-period real bond. Nominal bonds pay out one unit of money at the end of their maturity, and real bonds pay one unit of consumption. The values of the equity share index, nominal bonds and real bonds are denoted by $V^{e q}, V_{j}^{b n}$ and $V_{j}^{b r}$, respectively. ${ }^{36}$ Households also receive dividends from firms, $D$ (which are paid in money). Stocks and bonds from the previous period are revalued at the start of the new discrete period; we can think of them being sold off at the beginning of the new period.

Turning to the left hand side of the constraint, households make expenditures on consumption, $C$, lump-sum taxes, $T$, and a new portfolio of financial assets: money, stocks and bonds.

The household $a$ 's choice variables are consumption, $C(a)$; labour supply, $N(a)$; nominal money balances, $M(a)$; the equity share index, $S(a)$; nominal bonds, $B^{n}(a)$; and real bonds, $B^{r}(a)$. Denoting the Lagrange multiplier by $\Lambda(a)$, the first order conditions are

$$
\begin{gathered}
C_{t}(a): \quad\left(C_{t}(a)-H_{t}^{C}(a)\right)^{-\gamma^{C}}-\Lambda_{t}(a)=0 \\
N_{t}(a): \quad-\left(N_{t}(a)-H_{t}^{N}(a)\right)^{\gamma^{N}}+\Lambda_{t}(a) \frac{W_{t}}{P_{t}}=0 \\
M_{t}(a): \quad\left(\frac{M_{t}(a)}{P_{t}}\right)^{-\gamma^{M}} \frac{1}{P_{t}}-\frac{\Lambda_{t}(a)}{P_{t}}+E_{t}\left[\beta \frac{\Lambda_{t+1}(a)}{P_{t+1}}\right]=0 \\
S_{t}(a): \quad-\Lambda_{t}(a) \frac{V_{t}^{e q}}{P_{t}}+E_{t}\left[\beta \Lambda_{t+1}(a) \frac{V_{t+1}^{e q}+D_{t+1}}{P_{t+1}}\right]=0 \\
B_{j, t}^{n}(a): \quad-\Lambda_{t}(a) \frac{V_{j, t}^{b n}}{P_{t}}+E_{t}\left[\beta \Lambda_{t+1}(a) \frac{V_{j-1, t+1}^{b n}}{P_{t+1}}\right]=0, \quad j=1, \ldots, J \\
B_{j, t}^{r}(a): \quad-\Lambda_{t}(a) V_{j, t}^{b r}+E_{t}\left[\beta \Lambda_{t+1}(a) V_{j-1, t+1}^{b r}\right]=0, \quad j=1, \ldots, J
\end{gathered}
$$

\footnotetext{
${ }^{36}$ Note that $V^{e q}$ and $V^{b n}$ are denominated in nominal goods (units of money), whereas $V^{b r}$ is denominated in real goods (units of consumption).
} 
and

$$
\begin{aligned}
\Lambda(a): & C_{t}(a)+\frac{T_{t}(a)}{P_{t}}+\frac{M_{t}(a)}{P_{t}}+\frac{V_{t}^{e q}}{P_{t}} S_{t}(a) \\
+ & \sum_{j=1}^{J} \frac{V_{j, t}^{b n}}{P_{t}} B_{j, t}^{n}(a)+\sum_{j=1}^{J} V_{j, t}^{b r} B_{j, t}^{r}(a) \\
- & \frac{W_{t}}{P_{t}} N_{t}(a)-\frac{M_{t-1}(a)}{P_{t}}-\frac{V_{t}^{e q}+D_{t}}{P_{t}} S_{t-1}(a) \\
& -\sum_{j=1}^{J} \frac{V_{j-1, t}^{b n}}{P_{t}} B_{j, t-1}^{n}(a)-\sum_{j=1}^{J} V_{j-1, t}^{b r} B_{j, t-1}^{r}(a) \\
= & 0
\end{aligned}
$$

Aggregation of these first order conditions is straightforward. Households have identical preferences and are insured against idiosyncratic labour income risk. Households own firms and equity shares sum to one (ie, $\sum_{a=1}^{\infty} S_{t}(a)=1 \forall t$ ). All bonds are in zero net supply (ie, $\sum_{a=1}^{\infty} B_{t}^{b n}(a)=0 \forall t$ and $\sum_{a=1}^{\infty} B_{t}^{b r}(a)=0 \forall t$ ). The habit levels for consumption and leisure are assumed to be external, and follow lagged aggregate levels: $H^{C}=\chi^{C} C_{t-1}$ and $H^{L}=\chi^{L}\left(1-N_{t-1}\right)$. Defining the gross inflation rate as $\Pi_{t} \equiv \frac{P_{t}}{P_{t-1}}$, this yields aggregate expressions for marginal utility (A.1), labour supply (A.2), money demand (A.3), consumption Euler equations for equity (A.4), nominal bonds (A.5), real bonds (A.6) and the budget constraint (A.7):

$$
\begin{gathered}
\left(C_{t}-\chi^{C} C_{t-1}\right)^{-\gamma^{C}}=\Lambda_{t}, \\
\left(N_{t}-\chi^{N} N_{t-1}\right)^{\gamma^{N}}=\Lambda_{t} \frac{W_{t}}{P_{t}} \\
\left(\frac{M_{t}}{P_{t}}\right)^{-\gamma^{M}}=\Lambda_{t}\left(1-E_{t}\left[\beta \frac{\Lambda_{t+1}}{\Lambda_{t}} \frac{1}{\Pi_{t+1}}\right]\right), \\
\Lambda_{t} \frac{V_{t}^{e q}}{P_{t}}=E_{t}\left[\beta \Lambda_{t+1} \frac{V_{t+1}^{e q}+D_{t+1}}{P_{t+1}}\right], \\
\Lambda_{t} \frac{V_{j, t}^{b n}}{P_{t}}=E_{t}\left[\beta \Lambda_{t+1} \frac{V_{j-1, t+1}^{b n}}{P_{t+1}}\right], \quad j=1, . ., J \\
\Lambda_{t} V_{j, t}^{b r}=E_{t}\left[\beta \Lambda_{t+1} V_{j-1, t+1}^{b r}\right], \quad j=1, . ., J
\end{gathered}
$$

and

$$
C_{t}+\frac{T_{t}}{P_{t}}+\frac{M_{t}}{P_{t}}=\frac{W_{t}}{P_{t}} N_{t}+\frac{M_{t-1} / P_{t-1}}{\Pi_{t}}+\frac{D_{t}}{P_{t}}
$$




\section{A.2 Firms}

There is a continuum of intermediate goods firms and a single final good firm. The final goods sector is perfectly competitive and produces consumption and investment goods using intermediate goods. The intermediate goods sector is monopolistically competitive.

\section{A.2.1 The final goods sector}

The final good $Y_{t+i}$ is produced by bundling together a range of intermediate goods $Y_{t+i}(z)$ using the following Dixit-Stiglitz technology:

$$
Y_{t+i}=\left[\int_{0}^{1}\left(Y_{t+i}(z)\right)^{\frac{\eta-1}{\eta}} d z\right]^{\frac{\eta}{\eta-1}}
$$

where $\eta$ is the elasticity of substitution between the differentiated goods. Cost minimization by the final goods firm implies the following demand for each individual intermediate good:

$$
Y_{t+i}(z)=\left(\frac{P_{t+i}(z)}{P_{t+i}}\right)^{-\eta} Y_{t+i}
$$

where $P_{t}(z)$ is the price of the intermediate goods and $P_{t}$ is the price of the final good.

We can derive this in the following steps: given the cost minimisation problem

$$
\min \int_{0}^{1} P_{t}(z) Y_{t}(z) d z \quad \text { s.t. } Y_{t}=\left[\int_{0}^{1} Y_{t}(z)^{\frac{\eta-1}{\eta}} d z\right]^{\frac{\eta}{\eta-1}},
$$

and denoting by $\mu$ the Lagrangean on the Dixit-Stiglitz aggregator, the first-order condition for any individual input is

$$
\begin{aligned}
P_{t}(z)-\mu_{t}\left[\int_{0}^{1} Y_{t}(z)^{\frac{\eta-1}{\eta}} d z\right]^{\frac{1}{\eta-1}} Y_{t}(z)^{-\frac{1}{\eta}} & =0 \\
& \Rightarrow P_{t}(z)=\mu_{t} Y_{t}^{\frac{1}{\eta}} Y_{t}(z)^{-\frac{1}{\eta}} \\
& \Rightarrow Y_{t}(z)=\left[\frac{P_{t}(z)}{\mu_{t}}\right]^{-\eta} Y_{t},
\end{aligned}
$$

where $\mu$ has the interpretation as the Lagrange multiplier measuring the marginal 
value of producing an extra unit of the final good. This result implies that

$$
\begin{aligned}
Y_{t} & =\left[\int_{0}^{1}\left(\left[\frac{P_{t}(z)}{\mu_{t}}\right]^{-\eta} Y_{t}\right)^{\frac{\eta-1}{\eta}} d z\right]^{\frac{\eta}{\eta-1}} \\
& =\left(\frac{1}{\mu_{t}}\right)^{-\eta}\left[\int_{0}^{1} P_{t}(z)^{1-\eta} d z\right]^{\frac{\eta}{\eta-1}} Y_{t}
\end{aligned}
$$

which in turn implies that

$$
1=\left(\frac{1}{\mu_{t}}\right)^{-\eta}\left[\int_{0}^{1} P_{t}(z)^{1-\eta} d z\right]^{\frac{\eta}{\eta-1}}
$$

or

$$
\mu_{t}=\left[\int_{0}^{1} P_{t}(z)^{1-\eta} d z\right]^{\frac{1}{1-\eta}}=P_{t}
$$

Hence the price of the extra good will be set at its marginal value, and producers of intermediate goods face the following demand curve for their output:

$$
Y_{t}(z)=\left[\frac{P_{t}(z)}{P_{t}}\right]^{-\eta} Y_{t}
$$

\section{A.2.2 Intermediate-goods sector}

There is a continuum of intermediate goods firms indexed by $z$ that maximise profits, which are immediately paid out as dividends, $D(z)$, to shareholders. Following Rotemberg (1982), we assume that firms want to avoid changing their price $P(z)$ at a rate different than the steady-state gross inflation rate, $\bar{\Pi}$. Doing so incurs an intangible cost that does not affect cashflow (hence, profits) but enters the maximisation problem as a form of "disutility":

$$
\max E_{t} \sum_{i=0}^{\infty} \beta^{i} \frac{\Psi_{t+i}(z)}{\Psi_{t}(z)}\left\{D_{t+i}(z)-\frac{\chi^{P}}{2}\left(\frac{P_{t+i}(z)}{\bar{\Pi} P_{t+i-1}(z)}-1\right)^{2} P_{t+i} Y_{t+i}\right\},
$$

where $\beta^{i} \frac{\Psi_{t+i}(z)}{\Psi_{t}(z)}$ is the $z$ th firm's stochastic discount factor and $\chi^{P}$ measures the cost of adjusting prices (which is denominated in units of production). Dividends are the difference between revenue and expenses of paying for workers and investment, $I$ :

$$
D_{t+i}(z)=P_{t+i}(z) Y_{t+i}(z)-W_{t+i} N_{t+i}(z)-P_{t+i} I_{t+i}(z) .
$$


Each firm produces output $Y(z)$ by combining predetermined capital stock and currently rented labour in a Cobb-Douglas technology:

$$
Y_{t+i}(z)=A_{t+i} K_{t+i-1}^{\alpha}(z) N_{t+i}^{1-\alpha}(z) .
$$

Firms face a downward-sloping demand curve:

$$
Y_{t+i}(z)=\left(\frac{P_{t+i}(z)}{P_{t+i}}\right)^{-\eta} Y_{t+i} .
$$

In addition, firms face costs $\omega\left(I_{t+i}(z), K_{t+i-1}(z)\right)$ when changing the capital stock, with the capital accumulation identity given by

$$
K_{t+i}(z)=(1-\delta) K_{t+i-1}(z)+\omega\left(I_{t+i}(z), K_{t+i-1}(z)\right) K_{t+i-1}(z) .
$$

As is standard in the literature, we assume that $\omega(\cdot)$ is concave. Finally, total factor productivity $A_{t+i}$ is subject to a shock of the form

$$
\log \left(A_{t}\right)=\left(1-\rho^{A}\right) \log (\bar{A})+\rho^{A} \log \left(A_{t-1}\right)+\varepsilon_{t}^{A}, \quad \varepsilon_{t}^{A} \sim \text { i.i.d.N }\left(0, \sigma_{\varepsilon^{A}}^{2}\right) .
$$

Firms choose capital, $K(z)$; investment, $I(z)$; labour input, $N(z)$; and the price of their good, $P(z)$. Denoting the Lagrange multipliers on the market clearing condition and the capital accumulation identity by $\Upsilon(z)$ and $q(z)$, respectively, the Lagrangean is given by

$$
E_{t} \sum_{i=0}^{\infty} \beta^{i} \frac{\Psi_{t+i}(z)}{\Psi_{t}(z)}\left\{\begin{array}{c}
\left(\frac{P_{t+i}(z)}{P_{t+i}}\right)^{1-\eta} Y_{t+i}-\frac{W_{t+i}}{P_{t+i}} N_{t+i}(z)-I_{t+i}(z) \\
-\frac{\chi^{P}}{2}\left(\frac{P_{t+i}(z)}{\bar{\Pi} P_{t+i-1}(z)}-1\right)^{2} Y_{t+i} \\
-\Upsilon_{t+i}(z)\left(\left(\frac{P_{t+i}(z)}{P_{t+i}}\right)^{-\eta} Y_{t+i}-A_{t+i} K_{t+i-1}^{\alpha}(z) N_{t+i}^{1-\alpha}(z)\right) \\
-q_{t+i}(z)\left(\begin{array}{c}
K_{t+i}(z)-(1-\delta) K_{t+i-1}(z) \\
-\omega\left(I_{t+i}(z), K_{t+i-1}(z)\right) K_{t+i-1}(z)
\end{array}\right)
\end{array}\right\} .
$$

The first order conditions are given by

$$
\begin{gathered}
N_{t}(z): \quad-\frac{W_{t}}{P_{t}}+\Upsilon_{t}(1-\alpha) A_{t} K_{t-1}^{\alpha}(z) N_{t}^{-\alpha}(z)=0 \\
K_{t}(z): \quad E_{t}\left[\beta \frac{\Psi_{t+1}(z)}{\Psi_{t}(z)}\left(\begin{array}{c}
\Upsilon_{t+1}(z) \alpha A_{t+1} K_{t}^{\alpha-1}(z) N_{t+1}^{1-\alpha}(z) \\
1-\delta \\
\left.+q_{t+1}(z)\left(\begin{array}{c}
+\omega\left(I_{t+1}(z), K_{t}(z)\right) \\
+\omega_{K}\left(I_{t+1}(z), K_{t}(z)\right) K_{t}(z)
\end{array}\right)\right)
\end{array}\right)\right. \\
q_{t}(z): \quad-1+q_{t}(z) \omega_{I}\left(I_{t}(z), K_{t-1}(z)\right) K_{t-1}(z)=0
\end{gathered}
$$




$$
\begin{aligned}
& P_{t}(z): \quad\left(1-\eta_{t}\right)\left(\frac{P_{t}(z)}{P_{t}}\right)^{-\eta} \frac{Y_{t}}{P_{t}} \\
& -\chi^{P}\left(\frac{P_{t}(z)}{\bar{\Pi} P_{t-1}(z)}-1\right) \frac{Y_{t}}{\bar{\Pi} P_{t-1}(z)} \\
& +E_{t}\left[\beta \frac{\Psi_{t+1}(z)}{\Psi_{t}(z)} \chi^{P}\left(\frac{P_{t+1}(z)}{\bar{\Pi} P_{t}(z)}-1\right) \frac{P_{t+1}(z) Y_{t+1}}{\bar{\Pi} P_{t}^{2}(z)}\right] \\
& +\Upsilon_{t}(z) \eta\left(\frac{P_{t}(z)}{P_{t}}\right)^{-\eta-1} \frac{Y_{t}}{P_{t}} \\
= & 0 \quad\left(\frac{P_{t}(z)}{P_{t}}\right)^{-\eta} Y_{t}-A_{t} K_{t-1}^{\alpha}(z) N_{t}^{1-\alpha}(z)=0 \\
\Upsilon_{t}(z): \quad(1-\delta) K_{t-1}(z)-\omega\left(I_{t}(z), K_{t-1}(z)\right) K_{t-1}(z)=0 &
\end{aligned}
$$

It remains to specify the functional form of the capital adjustment cost function. We follow Jermann (1998) and Uhlig (2004) and assume that

$$
\omega\left(I_{t}(z), K_{t-1}(z)\right)=\frac{a_{1}}{1-\frac{1}{\chi^{K}}}\left(\frac{I_{t}}{K_{t-1}}\right)^{1-\frac{1}{\chi^{K}}}+a_{2} .
$$

The parameters $a_{1}$ and $a_{2}$ are chosen so that capital adjustment costs are zero in the deterministic steady state, which implies $\frac{\bar{I}}{\bar{K}}=\delta, \omega(\bar{I}, \bar{K})=\delta$ and $\omega_{K}(\bar{I}, \bar{K})=1$, where the bars indicate deterministic steady-state levels.

Aggregation for firms is straightforward. All firms set prices identically (in contrast to the Calvo price setting schema, in which firms are heterogeneous in price setting). Firms are owned by households, so that firm's adopt the discount rate of firms: $\Psi=\Lambda$. This yields aggregate equations for labour demand (A.9), investment (A.10), price setting (A.11), output (A.12), capital accumulation (A.13) and dividends (A.14):

$$
\begin{aligned}
& \frac{W_{t}}{P_{t}}=\Upsilon_{t}(1-\alpha) A_{t} K_{t-1}^{\alpha} N_{t}^{-\alpha},
\end{aligned}
$$

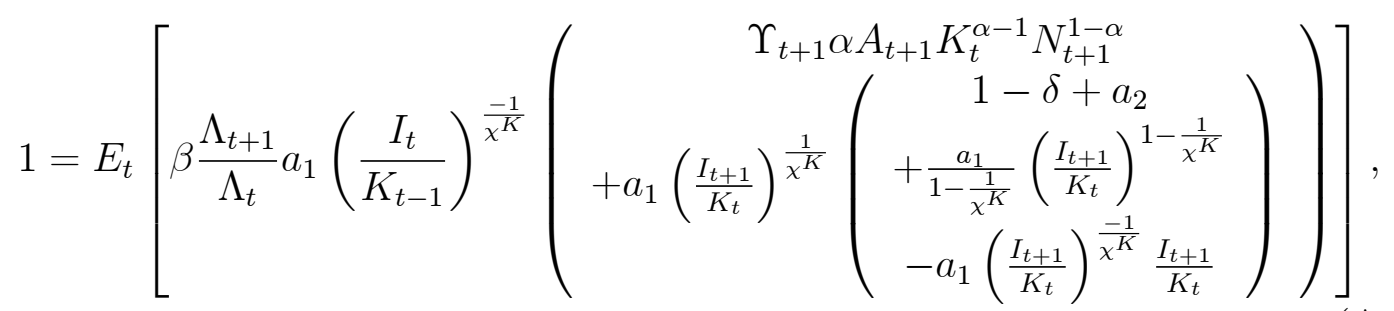




$$
\begin{gathered}
\Upsilon_{t}=\frac{\eta-1}{\eta}+\frac{\chi^{P}}{\eta}\left(\frac{\Pi_{t}}{\bar{\Pi}}-1\right) \frac{\Pi_{t}}{\bar{\Pi}} \\
-E_{t}\left[\beta \frac{\Lambda_{t+1}}{\Lambda_{t}} \frac{\chi^{P}}{\eta}\left(\frac{\Pi_{t+1}}{\bar{\Pi}}-1\right) \frac{\Pi_{t+1}}{\bar{\Pi}} \frac{y_{t+1}}{y_{t}}\right] \\
Y_{t}=A_{t} K_{t-1}^{\alpha} N_{t}^{1-\alpha} \\
K_{t}=(1-\delta) K_{t-1}+\left(\frac{a_{1}}{1-\frac{1}{\chi^{K}}}\left(\frac{I_{t}}{K_{t-1}}\right)^{1-\frac{1}{\chi^{K}}}+a_{2}\right) K_{t-1}, \\
\frac{D_{t}}{P_{t}}=Y_{t}-\frac{W_{t}}{P_{t}} N_{t}-I_{t} .
\end{gathered}
$$

\section{A.3 Government and monetary authority}

There is no government spending nor borrowing. The nominal government budget constraint is given by

$$
T_{t}=M_{t}-M_{t-1} .
$$

The government is thus making net transfer payments to the public that are financed by printing money.

The central bank provides a nominal anchor. In contrast to households and firms which follow an optimising strategy, the central bank follows a simple instrument rule:

$$
r_{1, t}^{c b}=\theta^{R} r_{1, t-1}^{c b}+\left(1-\theta^{R}\right) \theta^{\pi} \pi_{t}+\varepsilon_{t}^{R},
$$

where lower case letters denote log deviations from steady-state. The parameter $\theta^{R} \in[0,1)$ governs the degree of interest rate smoothing and $\theta^{\pi}>1$ governs the degree to which the central bank reacts to deviations of inflation from steady state. The monetary rule is subject to a shock $\varepsilon_{t}^{R}$ that has an i.i.d. normal distribution with mean zero and variance $\sigma_{\varepsilon^{R}}^{2}$.

\section{A.4 Asset pricing}

Prices and yields for nominal and real bonds follow from the Euler equations (A.5) and (A.6).

A real zero coupon bond returns one unit of consumption at maturity. So, for $j=1$, (A.6) becomes

$$
V_{1, t}^{b r}=E_{t}\left[\beta \frac{\Lambda_{t+1}}{\Lambda_{t}} V_{0, t+1}^{b r}\right]=E_{t}\left[\beta \frac{\Lambda_{t+1}}{\Lambda_{t}}\right],
$$


with the corresponding real yield

$$
R_{1, t+1}^{b r}=\frac{1}{V_{1, t}^{b r}}
$$

This is the risk-free real interest rate.

For $j=2$, equation (A.6) becomes

$$
V_{2, t}^{b r}=E_{t}\left[\beta \frac{\Lambda_{t+1}}{\Lambda_{t}} V_{1, t+1}^{b r}\right]
$$

The term $V_{1, t+1}^{b r}$ on the right-hand-side of the above equation is the price of a real bond of original maturity $j=2$ with one period left to maturity. Assuming no arbitrage, this price will equal the price of a bond of maturity $j=1$ issued next period. Bond prices (and from them yields) can thus be defined recursively, with the real price and real yield for any real bond of maturity $j$ given by

$$
V_{j, t}^{b r}=E_{t}\left[\beta \frac{\Lambda_{t+1}}{\Lambda_{t}} V_{j-1, t+1}^{b r}\right]
$$

and

$$
R_{j, t+1}^{b r}=\left(V_{j, t}^{b r}\right)^{-\frac{1}{j}}
$$

Nominal bond prices and nominal yields can be calculated in the same fashion from equation (A.5), with the nominal prices and nominal yields for a one-period and for a $j$-period bond given by

$$
V_{1, t}^{b n}=E_{t}\left[\beta \frac{\Lambda_{t+1}}{\Lambda_{t}} \frac{1}{\Pi_{t+1}}\right]
$$

and

$$
R_{1, t+1}^{b n} \equiv \frac{1}{V_{1, t}^{b n}}
$$

Correspondingly,

$$
V_{j, t}^{b n}=E_{t}\left[\beta \frac{\Lambda_{t+1}}{\Lambda_{t}} \frac{1}{\Pi_{t+1}} V_{j-1, t+1}^{b n}\right]
$$

and

$$
R_{j, t+1}^{b n}=\left(V_{j, t}^{b n}\right)^{-\frac{1}{j}}
$$

The Euler equation (A.4) implies $1=E_{t}\left[\beta \frac{\Lambda_{t+1}}{\Lambda_{t}} \frac{V_{t+1}^{e q}+D_{t+1}}{V_{t}^{e q}} \frac{P_{t}}{P_{t+1}}\right]$. We define the one-period real holding period return on equity, $R^{e q}$, as

$$
R_{t+1}^{e q}=\frac{V_{t+1}^{e q}+D_{t+1}}{V_{t}^{e q}} \frac{1}{\Pi_{t+1}} .
$$




\section{A.5 Market clearing}

As noted, intermediate firms behave identically and are owned by the representative household, so that the stochastic discount factor of all firms is the same as the stochastic discount factor of the representative household. In addition, the return on equity must equal the return on capital. The latter is given by the firm's Euler equation (A.10), such that

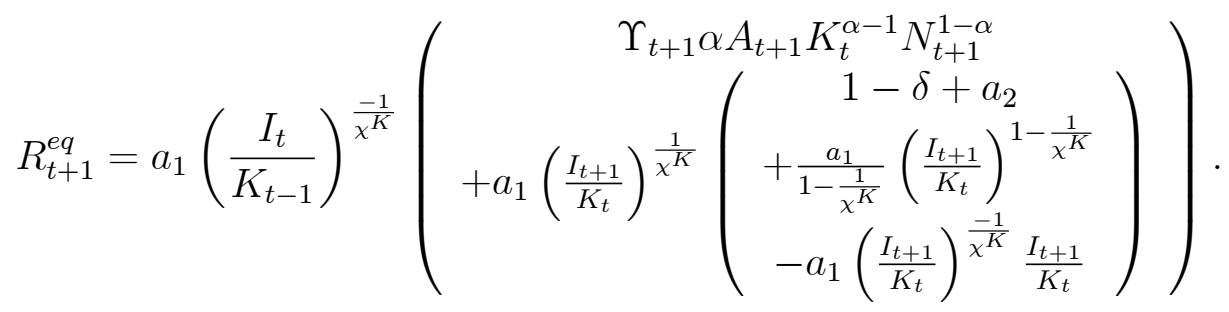

In the absence of arbitrage opportunities, the one-period nominal interest rate set by the central bank in its open market operations must equal the nominal interest rate available on one-period nominal zero coupon bonds:

$$
R_{t}^{c b}=R_{1, t+1}^{b n}
$$

\section{A.6 The system}

The core of the macro system has 14 equations in 14 unknowns for the productivity process (A.8), marginal utility (A.1), labour supply (A.2), money demand (A.3), equity values (A.4), the household budget constraint (A.7), labour demand (A.9), the investment Euler equation (A.10), the mark-up (A.11), output (A.12), capital accumulation (A.13), dividends (A.14), taxation (A.15), and the monetary policy rule (A.16). 


\section{B Tables}

Table 1: Stochastic averages for macro variables from the flex-price model subject to productivity shocks

\begin{tabular}{|l|c|c|}
\cline { 2 - 3 } \multicolumn{1}{c|}{} & Deterministic & Stochastic \\
\hline Output & 1.1157 & 1.1176 \\
\hline Capital:output & 8.5714 & 8.5924 \\
\hline Investment & 0.2391 & 0.2404 \\
\hline Consumption:output & 0.7857 & 0.7850 \\
\hline Real wages & 1.7858 & 1.7899 \\
\hline Employment & 0.3332 & 0.3333 \\
\hline
\end{tabular}

Table 2: Asset returns from the flex-price model subject to productivity shocks

\begin{tabular}{|l|c|c|c|c|c|c|c|}
\cline { 2 - 8 } \multicolumn{1}{c|}{} & Deterministic & \multicolumn{6}{c|}{ Stochastic } \\
\cline { 2 - 8 } \multicolumn{1}{c|}{} & $R$ & $R_{1}$ & $R^{e q}$ & $R^{e q}-R_{1}$ & $R_{40}$ & $R_{40}-R_{1}$ & $R_{1}^{n}-R_{1}^{r}-\pi_{1}$ \\
\hline Real & 4.06 & 3.06 & 5.49 & 2.43 & 3.98 & 0.92 & \\
\hline Nominal & 4.06 & 3.70 & & & 3.56 & -0.14 & 0.35 \\
\hline
\end{tabular}

$R_{1}=$ return on a one-period bond; $R_{40}=$ return on a fourty-period bond; $R^{e q}-R_{1}=$ equity risk premium (ERP); $R_{40}-R_{1}=$ term spread (TS);

$$
R_{1}^{n}-R_{1}^{r}-\pi_{1}=\text { inflation risk premium. }
$$

All returns are annualised and in percentage terms, spreads are in percentage points.

Table 3: Variations in asset returns from the flex-price model subject to productivity shocks with changes in real rigidities

\begin{tabular}{|l|c|c|c|c|c|}
\cline { 2 - 6 } \multicolumn{1}{c|}{} & Base case & $\begin{array}{c}\text { No real } \\
\text { rigidities }\end{array}$ & $\begin{array}{c}\text { No capital } \\
\text { adjustment } \\
\text { costs }\end{array}$ & $\begin{array}{c}\text { No labour } \\
\text { habits }\end{array}$ & $\begin{array}{c}\text { No consumption } \\
\text { habits }\end{array}$ \\
\hline$\chi^{P}$ & 0 & 0 & 0 & 0 & 0 \\
$\chi^{C}$ & 0.82 & 0 & 0.82 & 0.82 & 0 \\
$\chi^{N}$ & 0.82 & 0 & 0.82 & 0 & 0.82 \\
$\chi^{K}$ & 0.3 & 30,000 & 30,000 & 0.3 & 0.3 \\
\hline ERP & 2.43 & 0.0330 & 0.0426 & 0.5769 & 0.6036 \\
\hline TSr & 0.92 & -0.0013 & 0.0012 & 0.2630 & 0.2741 \\
\hline TSn & -0.14 & 0.0170 & 0.0244 & -0.0242 & -0.0191 \\
\hline
\end{tabular}

TSr $=$ real term spread; TSn $=$ nominal term spread.

All returns are annualised and in percentage terms, spreads are in percentage points. 
Table 4: Asset returns from the sticky-price model subject to productivity shocks

\begin{tabular}{|l|c|c|c|c|c|c|c|}
\cline { 2 - 8 } \multicolumn{1}{c|}{} & Deterministic & \multicolumn{6}{c|}{ Stochastic } \\
\cline { 2 - 8 } \multicolumn{1}{c|}{} & $R$ & $R_{1}$ & $R^{e q}$ & $R^{e q}-R_{1}$ & $R_{40}$ & $R_{40}-R_{1}$ & $R_{1}^{n}-R_{1}^{r}-\pi_{1}$ \\
\hline Real & 4.06 & 3.89 & 4.24 & 0.35 & 4.02 & 0.13 & \\
\hline Nominal & 4.06 & 3.85 & & & 3.85 & -0.00 & 0.09 \\
\hline
\end{tabular}

All returns are annualised and in percentage terms, spreads are in percentage points.

Table 5: Asset returns from the sticky-price model subject to monetary policy shocks

\begin{tabular}{|l|c|c|c|c|c|c|c|}
\cline { 2 - 8 } \multicolumn{1}{c|}{} & Deterministic & \multicolumn{6}{c|}{ Stochastic } \\
\cline { 2 - 8 } \multicolumn{1}{c|}{} & $R$ & $R_{1}$ & $R^{e q}$ & $R^{e q}-R_{1}$ & $R_{40}$ & $R_{40}-R_{1}$ & $R_{1}^{n}-R_{1}^{r}-\pi_{1}$ \\
\hline Real & 4.06 & 3.96 & 4.19 & 0.23 & 4.06 & 0.10 & \\
\hline Nominal & 4.06 & 3.40 & & & 3.56 & 0.15 & -0.14 \\
\hline
\end{tabular}

All returns are annualised and in percentage terms, spreads are in percentage points. 


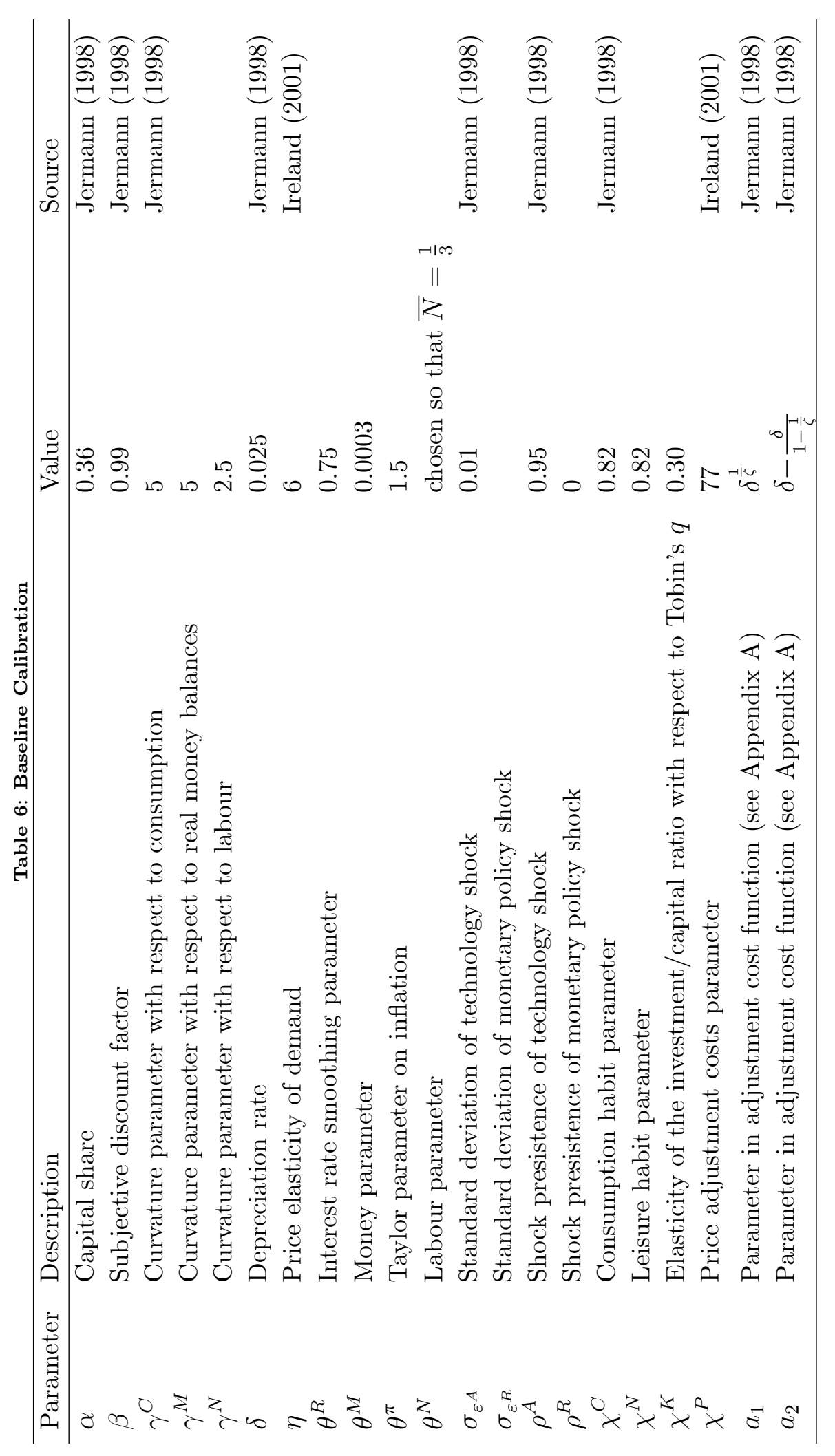




\section{Figures}

Figure 1: Impulse responses in the flex-price model following a productivity shock (percentage deviations from deterministic steady state)
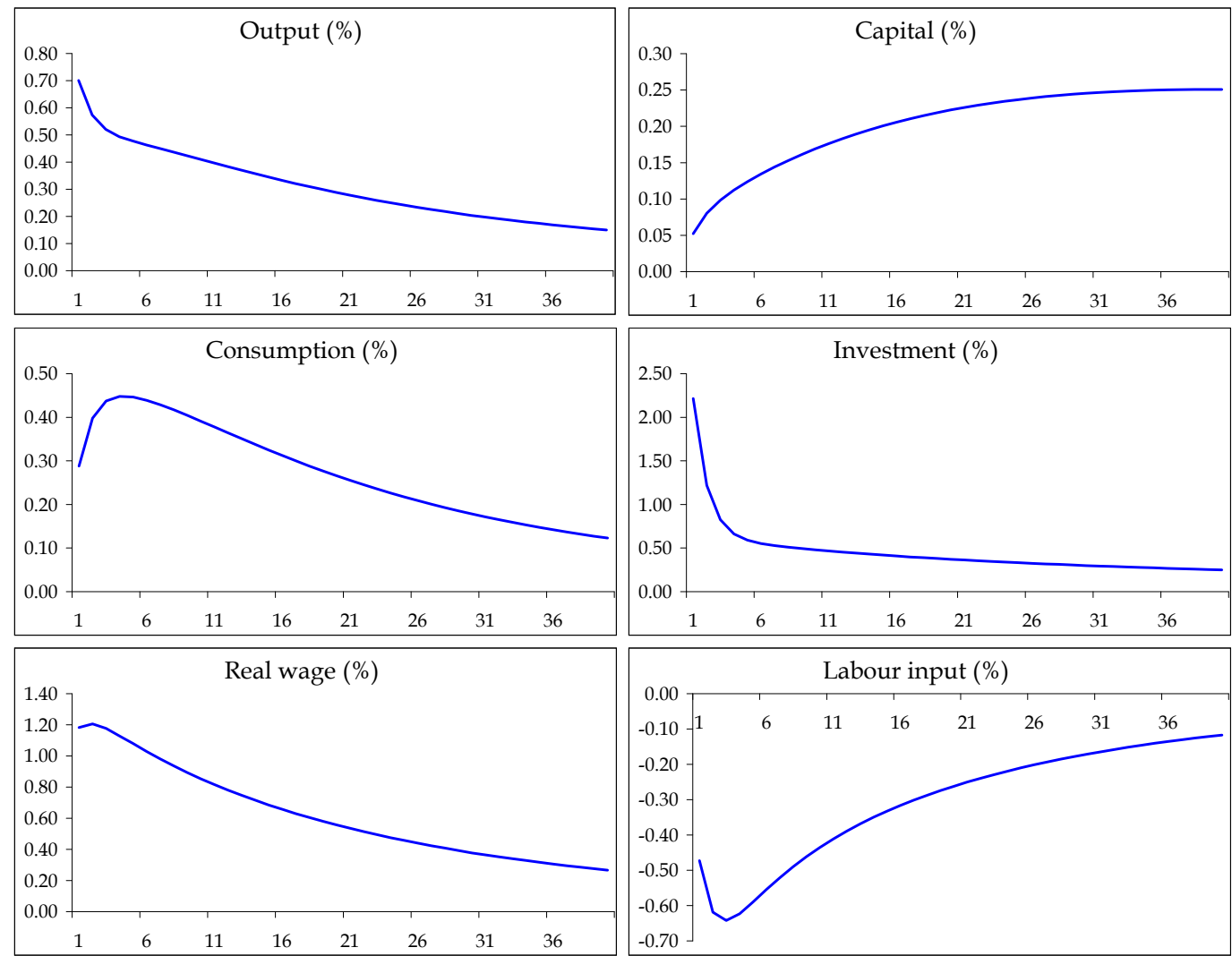
Figure 2: Impulse responses in the flex-price model following a productivity shock (percentage and percentage point deviations from steady state)
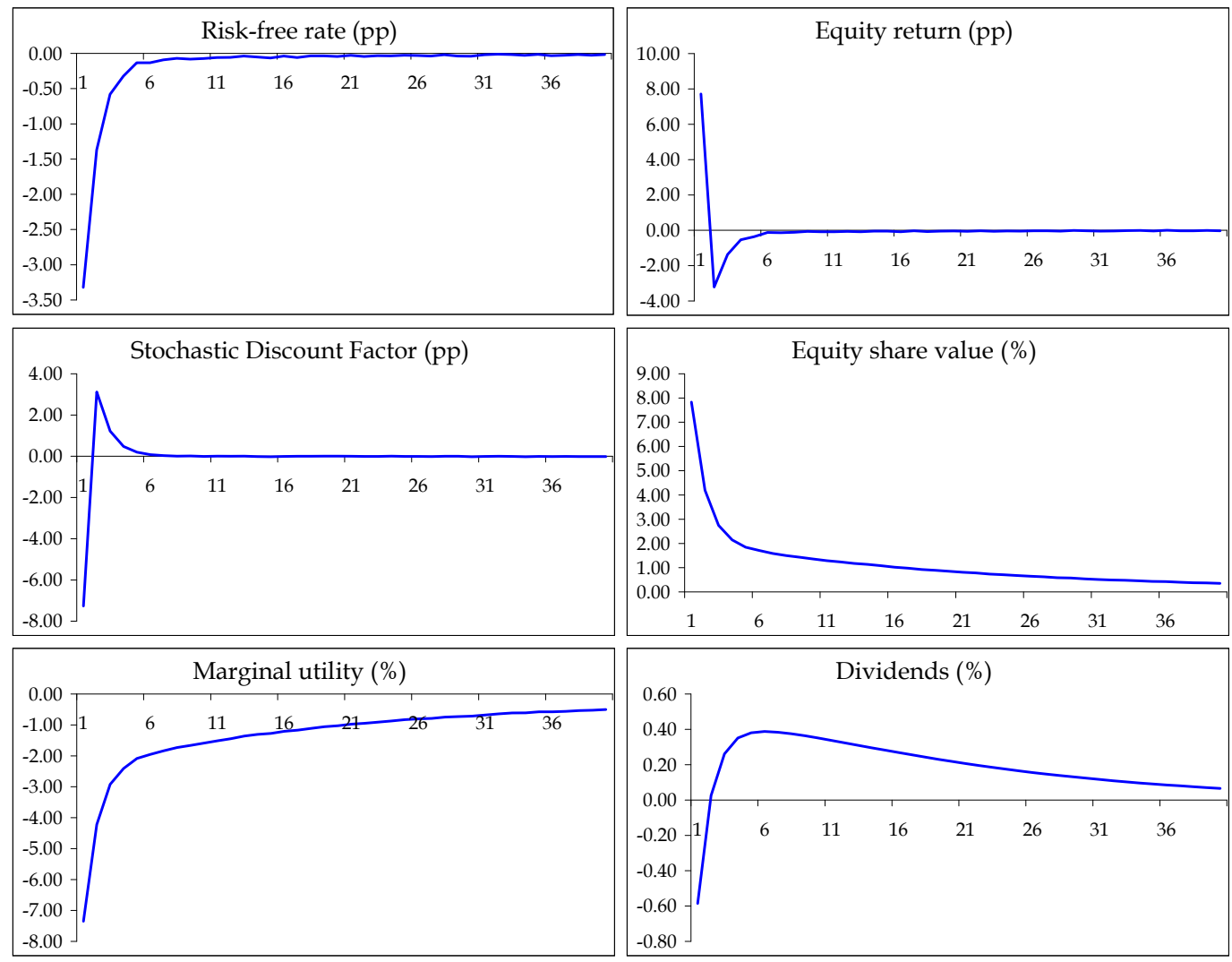
Figure 3: Real and nominal yield curves in the flex-price model: the case of productivity shocks (spot rates; annualised yields)

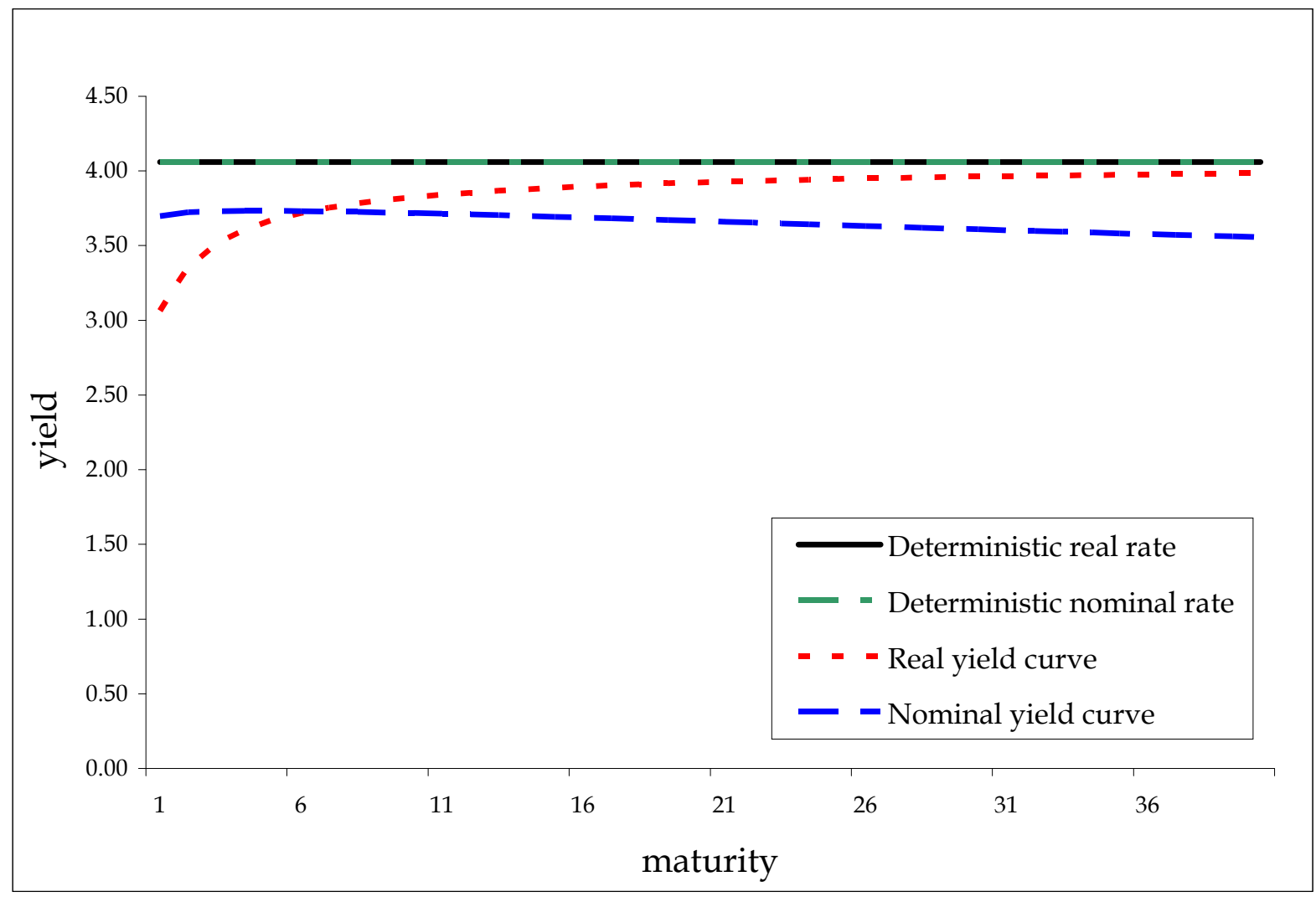


Figure 4: Sensitivity analysis: impulse responses in the flex-price model following a productivity shock (percentage deviations from steady state)
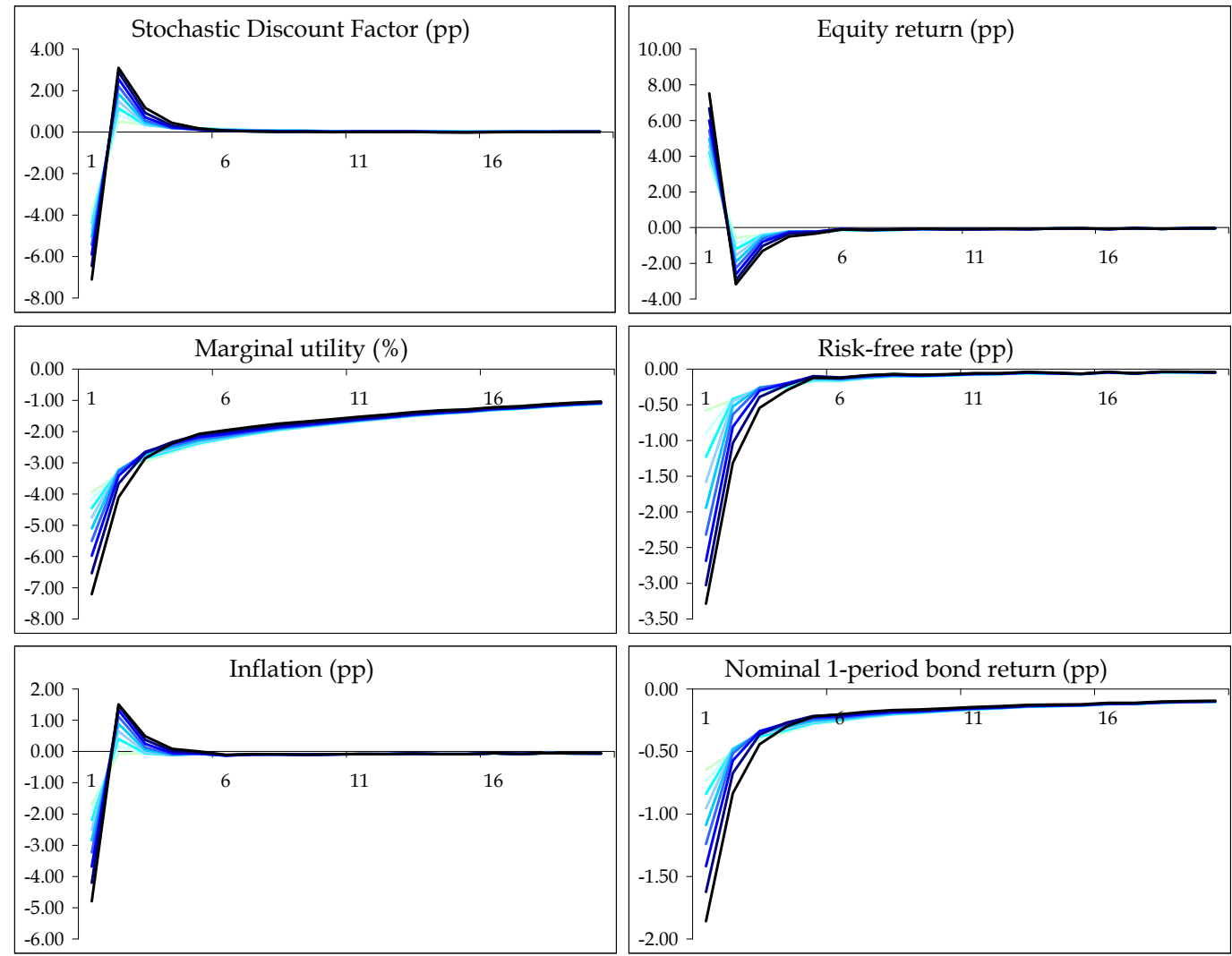
Figure 5: Sensitivity analyisis: stochastic means of asset pricing indicators in the flex-price model: the case of productivity shocks
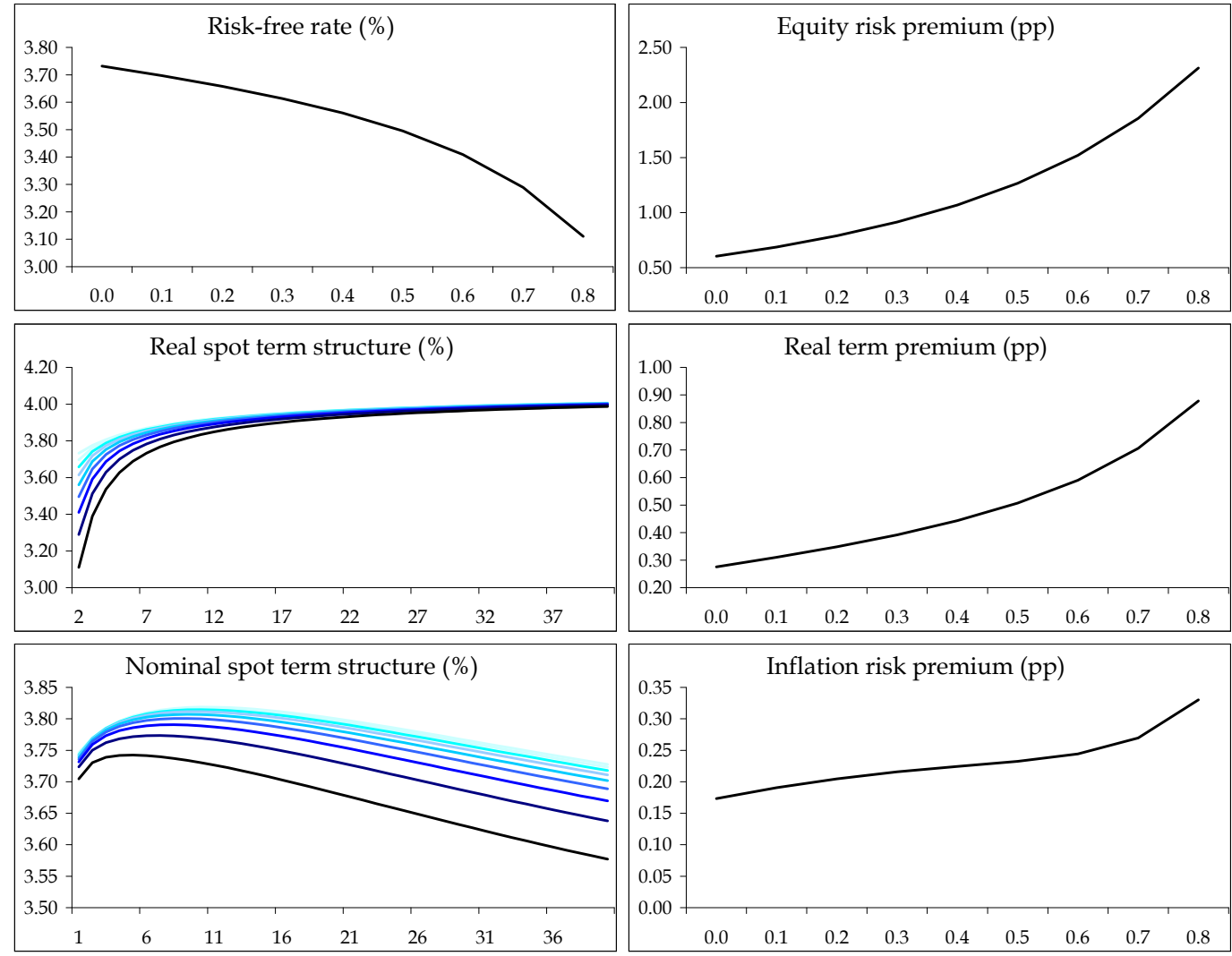
Figure 6: Real and nominal yield curves in the flex-price model: the case of monetary policy shocks (spot rates; annualised yields)

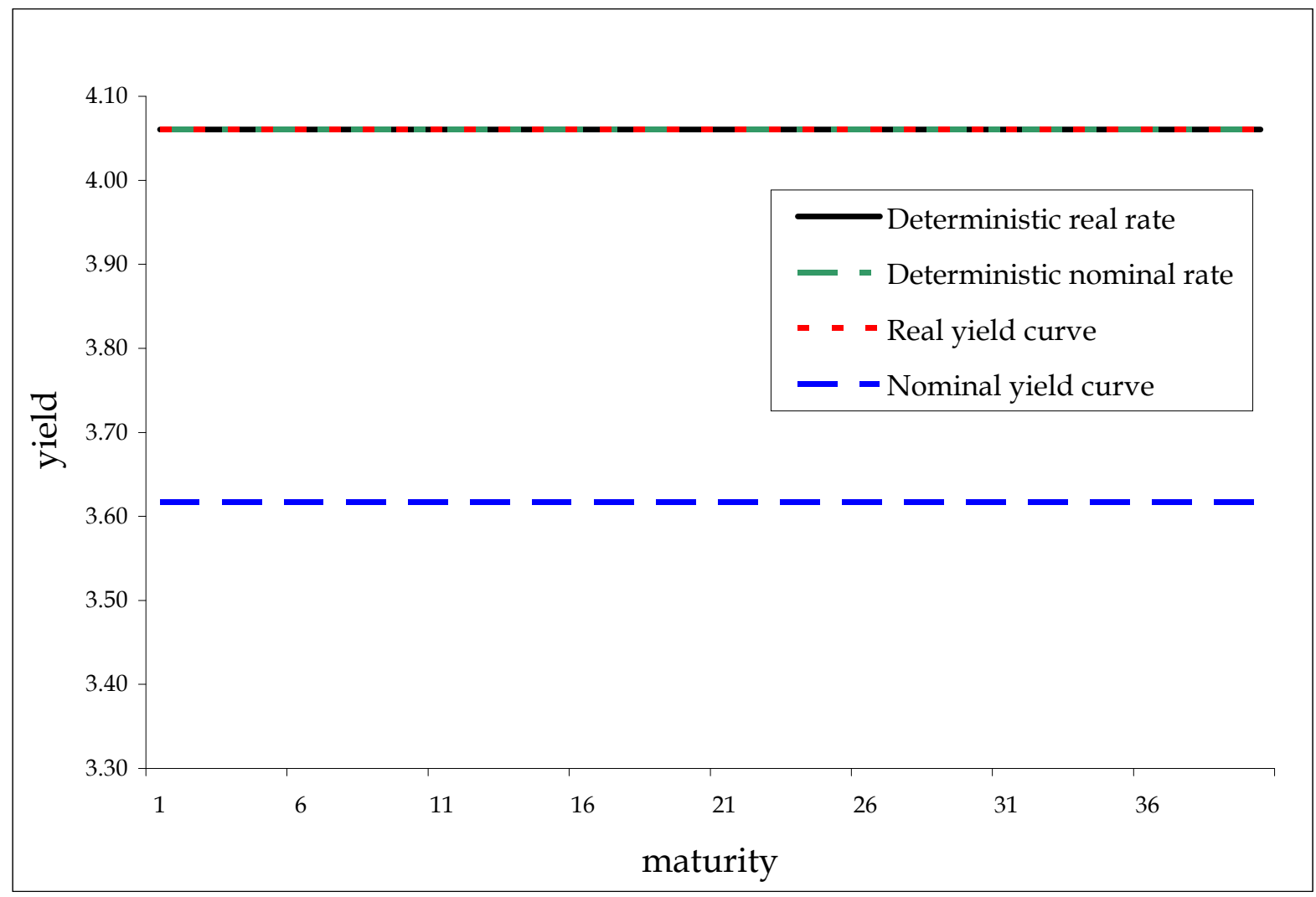


Figure 7: Impulse responses in the sticky-price model following a productivity shock (percentage deviations from steady state)
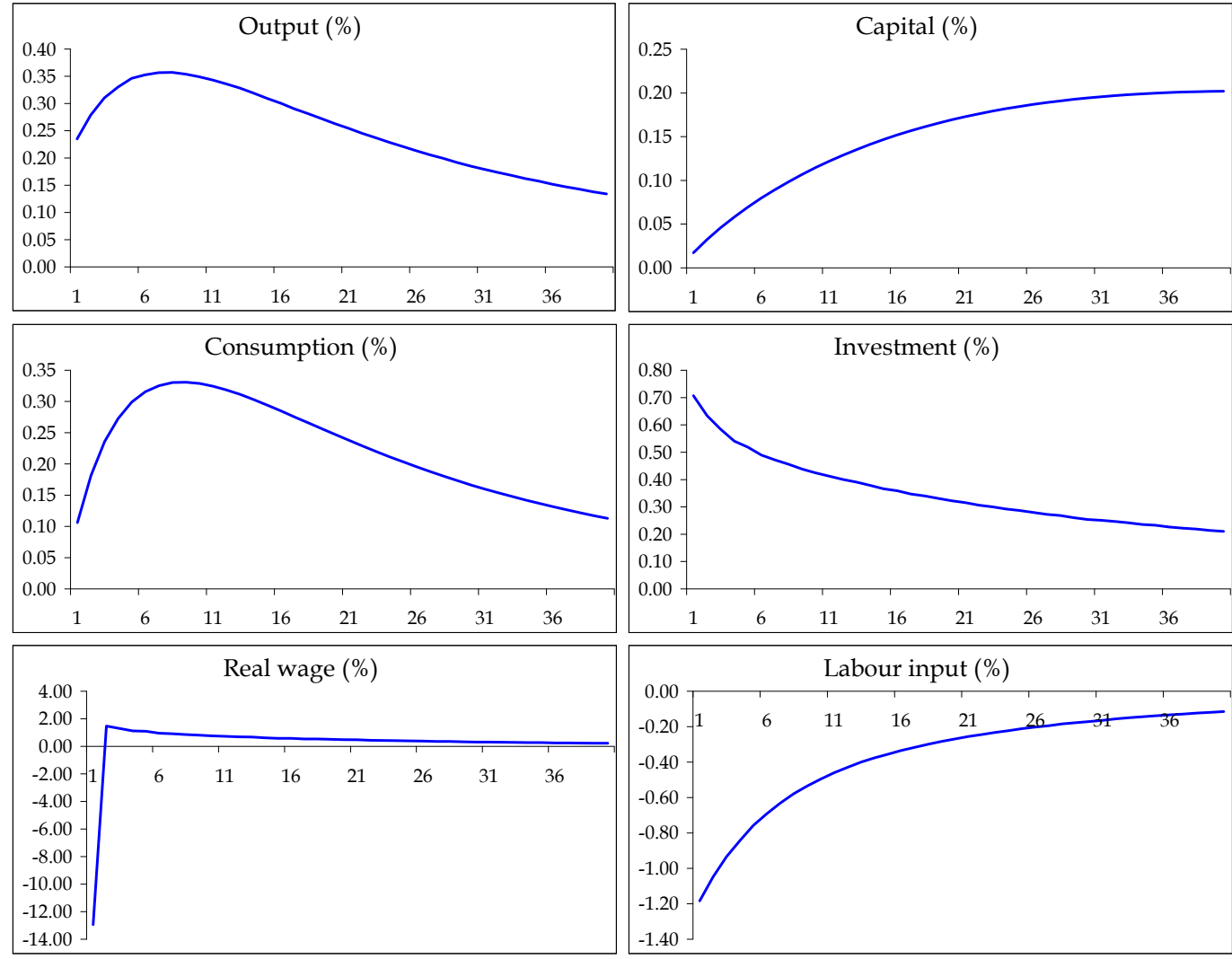
Figure 8: Impulse responses in the sticky-price model following a productivity shock (percentage and percentage point deviations from steady state)
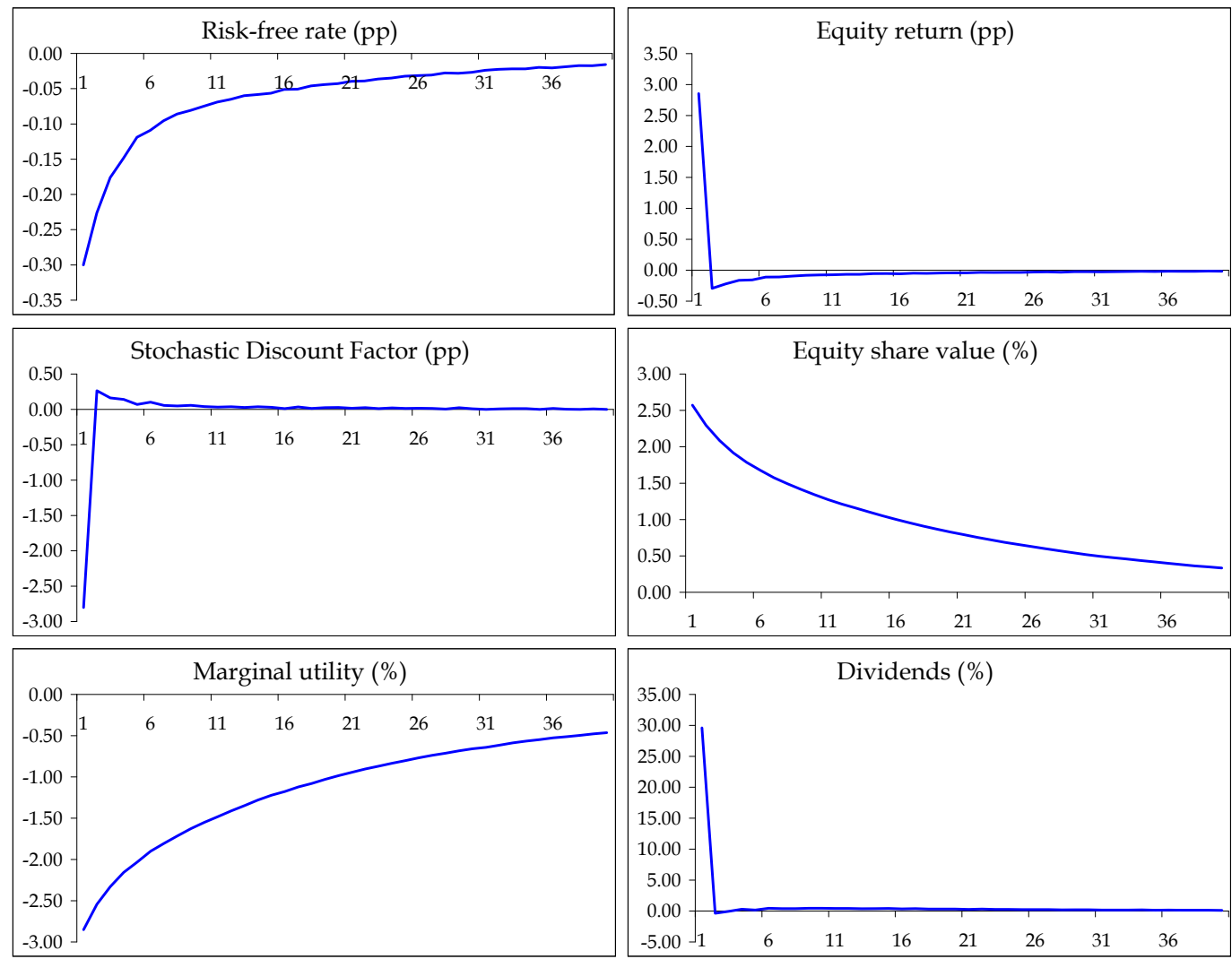
Figure 9: Real and nominal yield curves in the sticky-price model: the case of productivity shocks (spot rates; annualised yields)

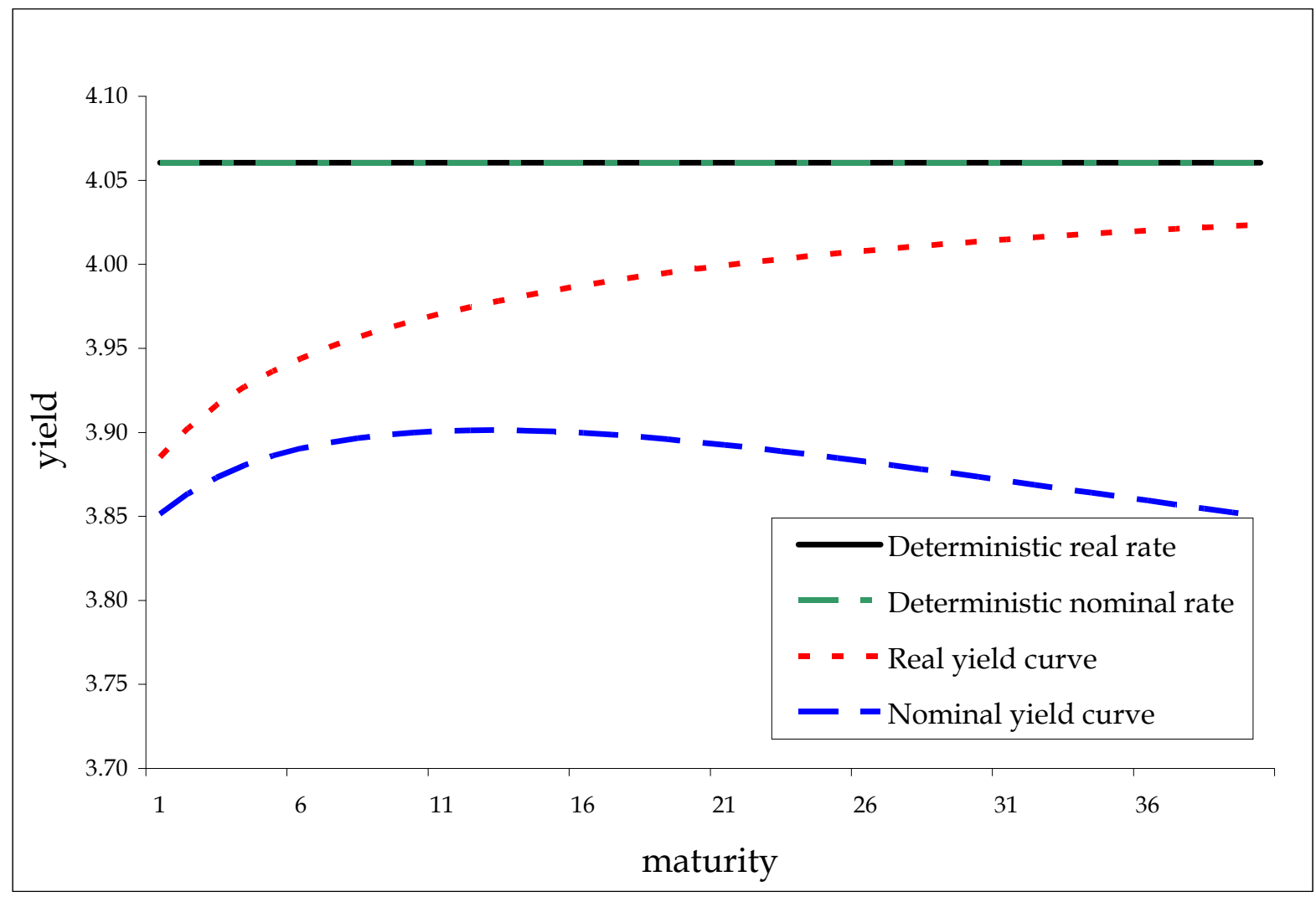


Figure 10: Sensitivity analysis: impulse responses in the sticky-price model following a productivity shock (percentage deviations from steady state)
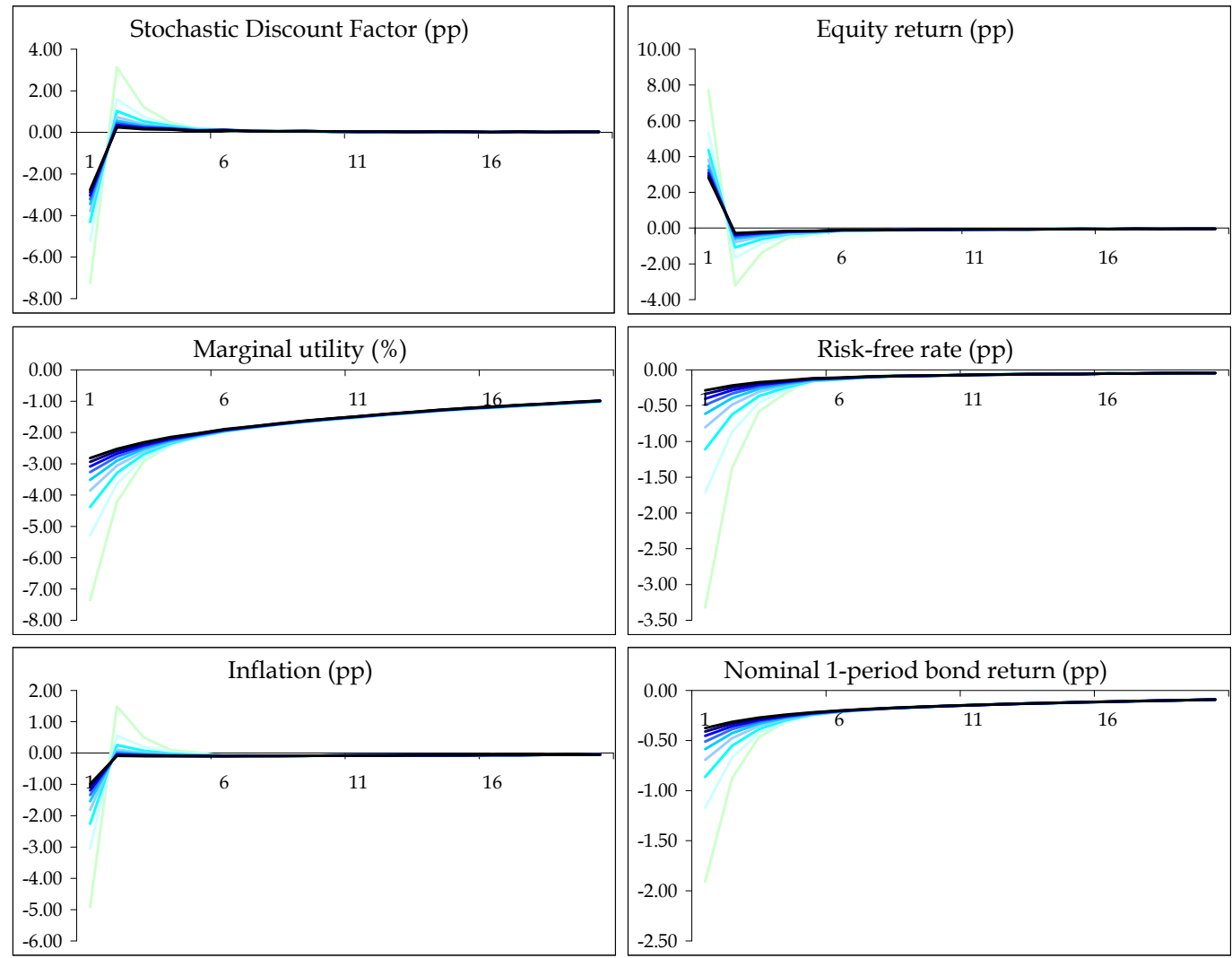
Figure 11: Sensitivity analysis: stochastic means of asset pricing indicators in the sticky-price model: the case of a productivity shock
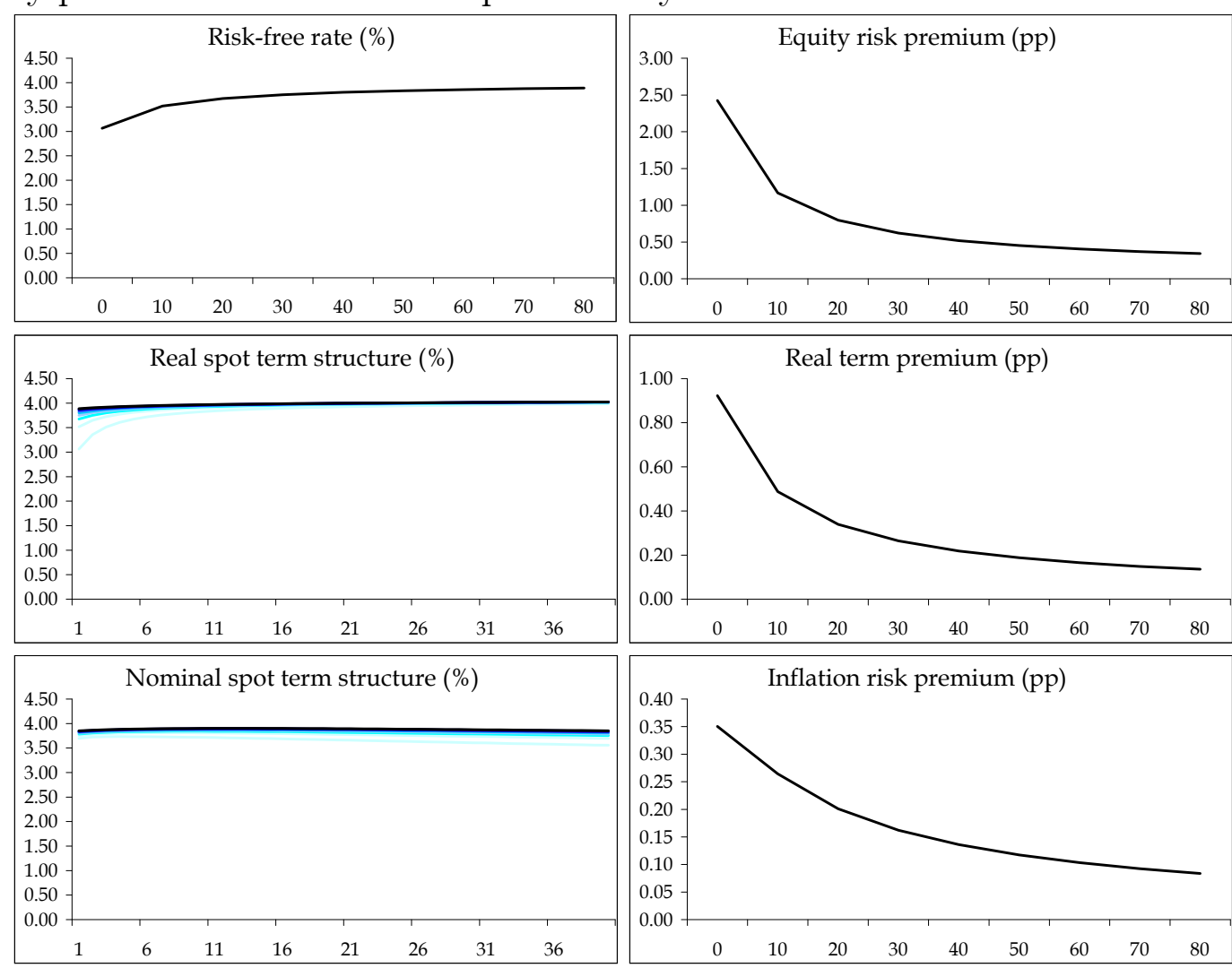
Figure 12: Impulse responses in the sticky-price model following a monetary policy shock (percentage deviations from steady state)
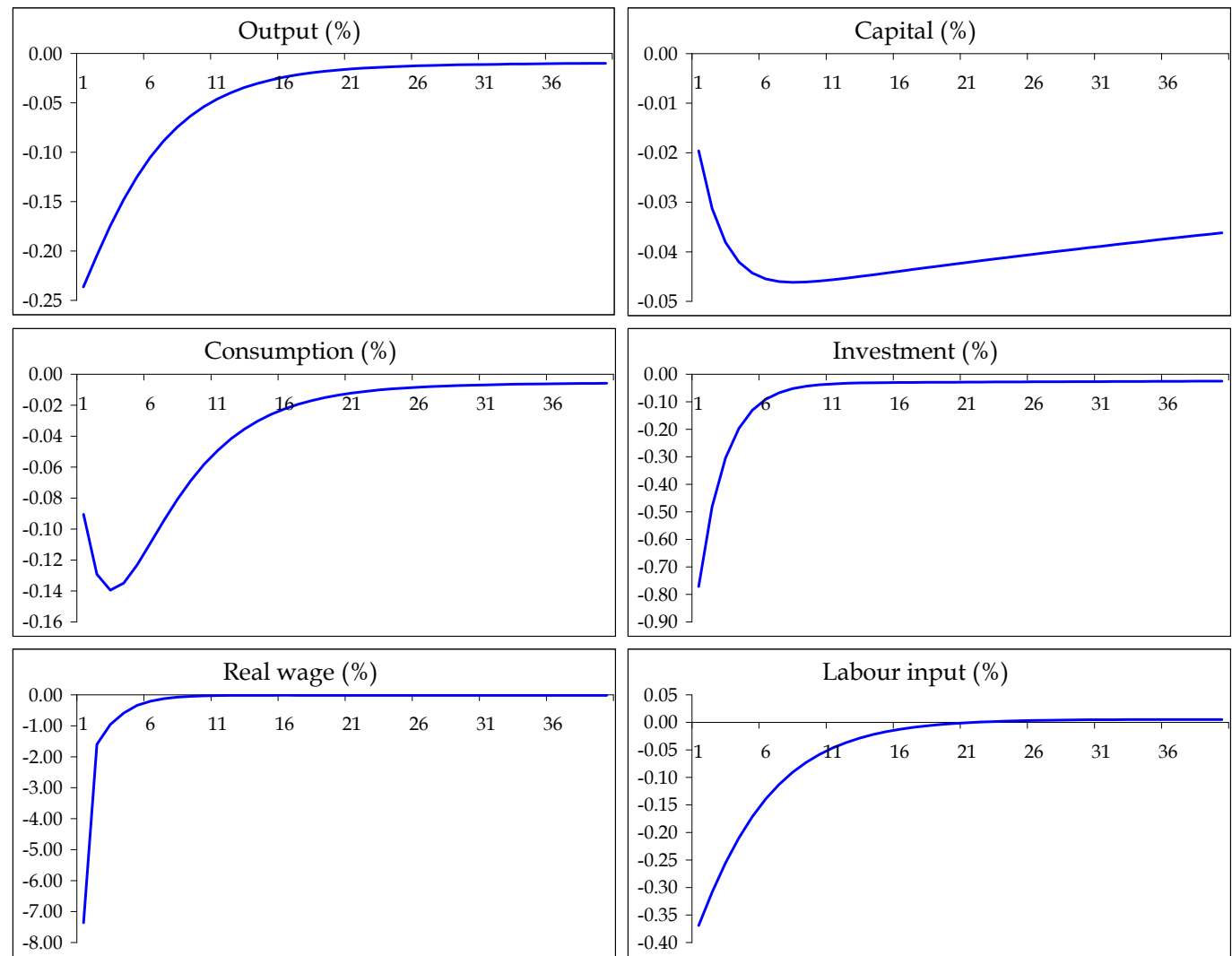
Figure 13: Impulse responses in the sticky-price model following a monetary policy shock (percentage deviations from steady state)
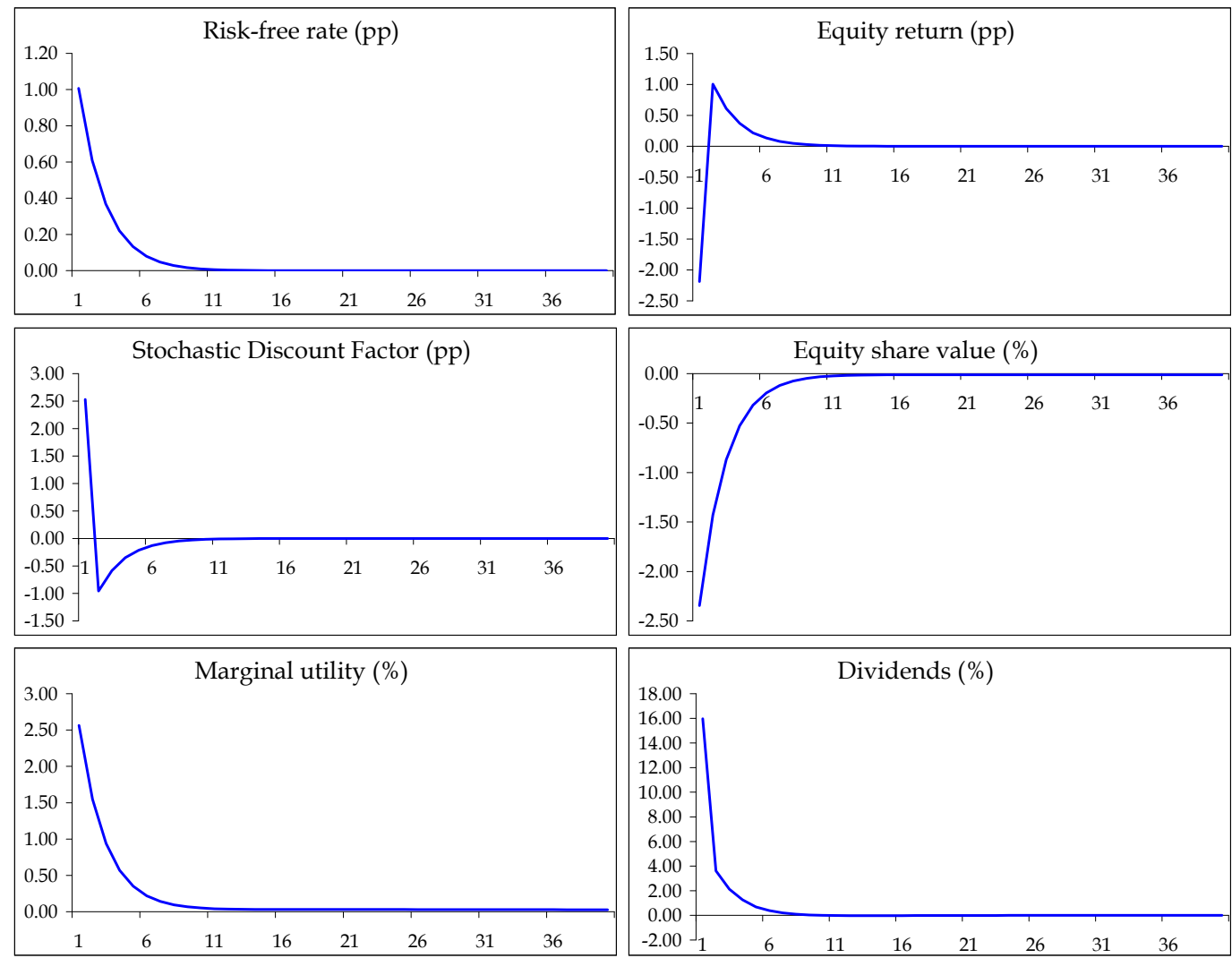
Figure 14: Real and nominal yield curves in the sticky-price model: the case of monetary policy shocks (spot rates; annualised yields)

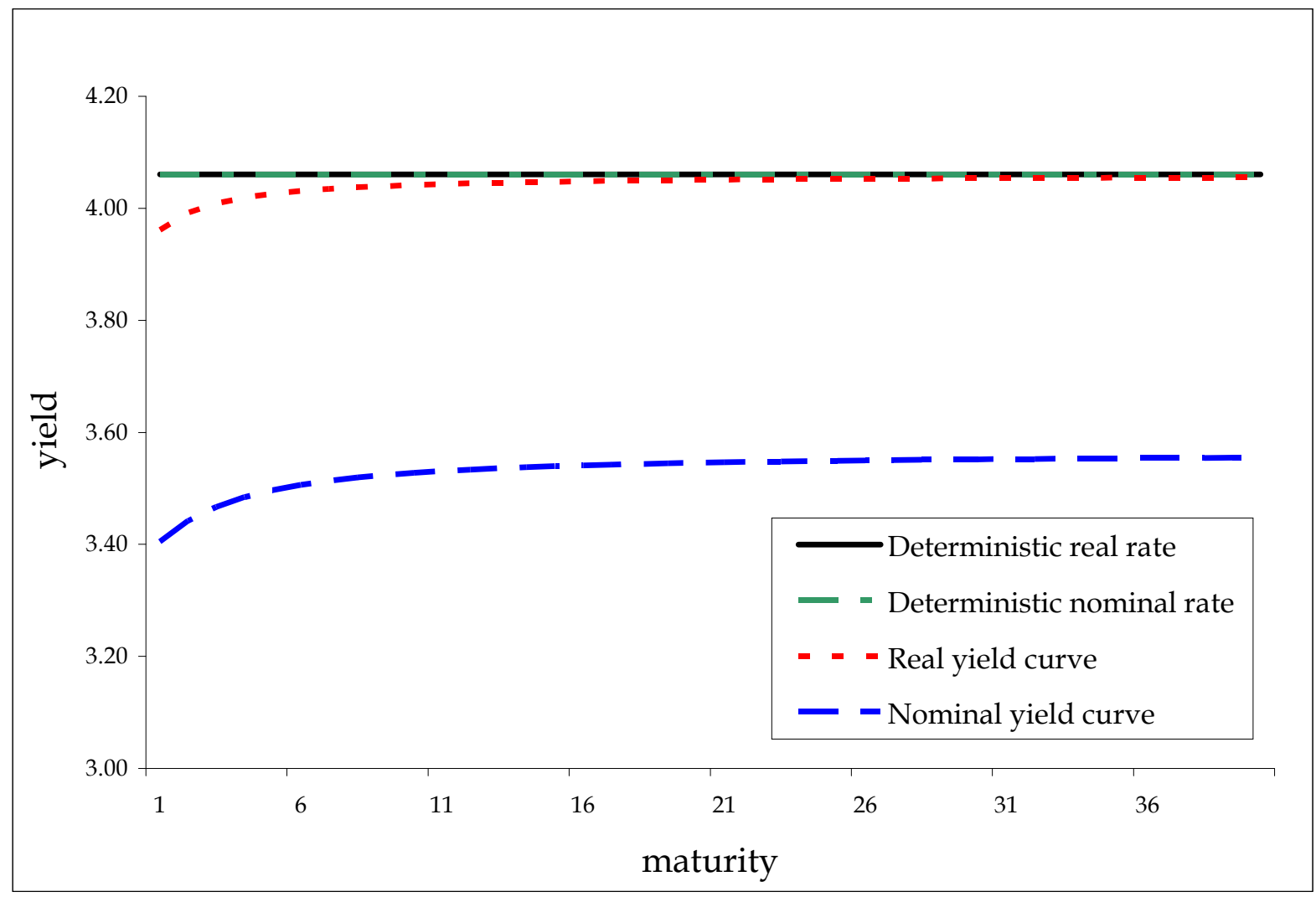


Figure 15: Sensitivity analysis: impulse responses in the sicky-price model following a monetary policy shock (percentage deviations from steady state)
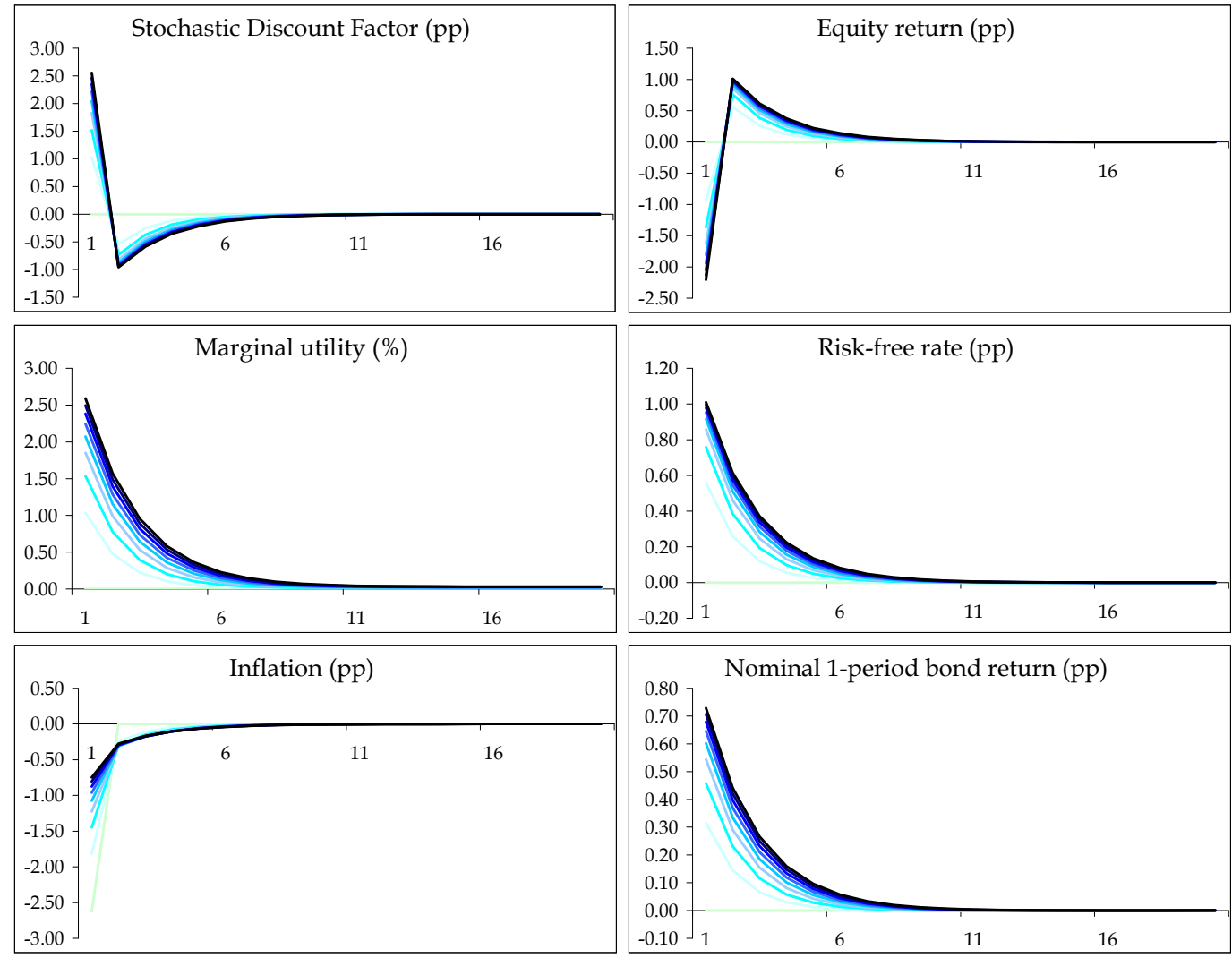
Figure 16: Sensitivity analysis: stochastic means of asset pricing indicators in the sticky-price model: the case of a monetary policy shock
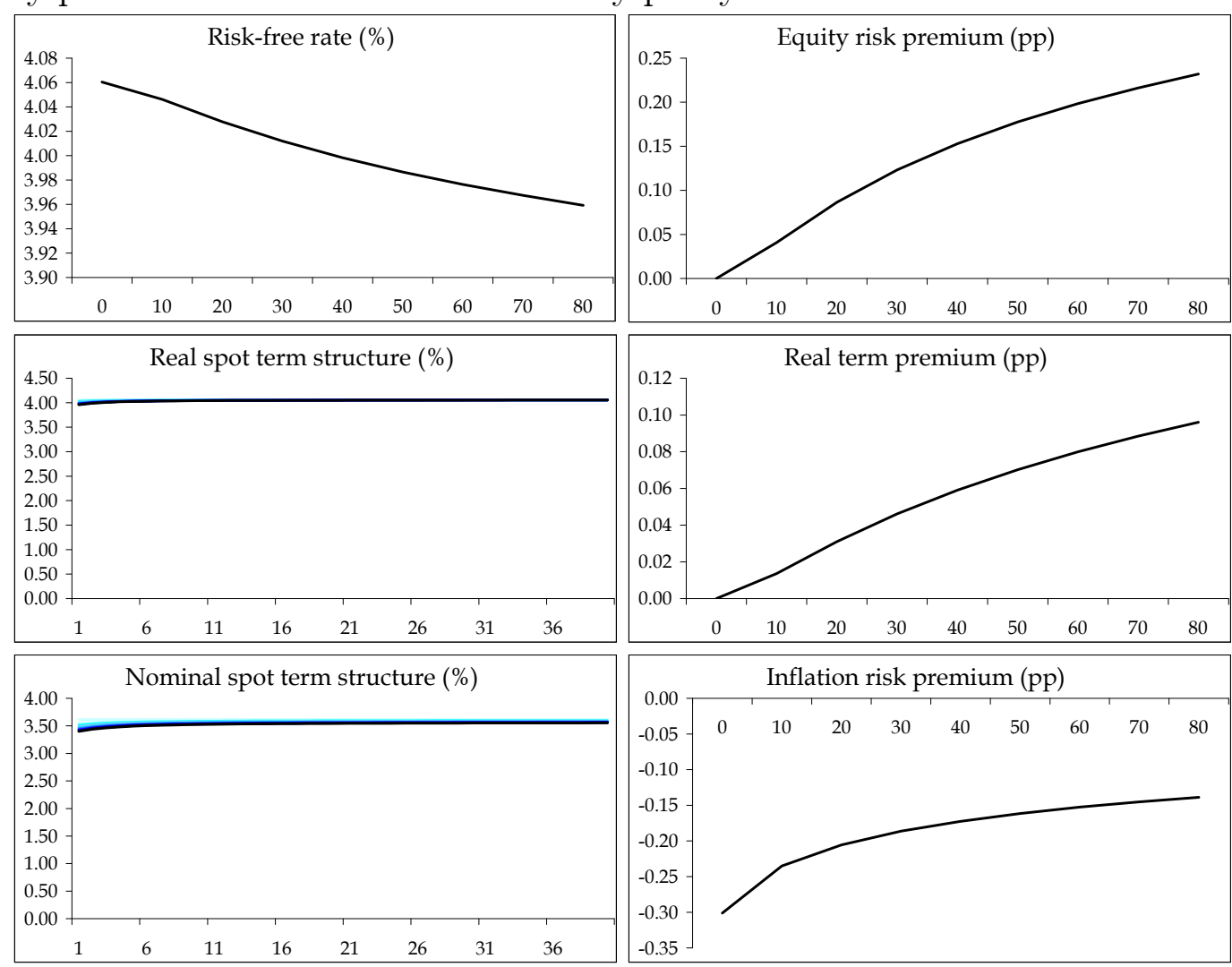